\title{
Review Article \\ Imaging Findings and Evaluation of Metabolic Bone Disease
}

\author{
Anish A. Patel, Rohit Ramanathan, Joshua Kuban, and Marc H. Willis \\ Department of Radiology, Baylor College of Medicine, One Baylor Plaza, Houston, TX 77030, USA \\ Correspondence should be addressed to Anish A. Patel; anishp@bcm.edu
}

Received 21 October 2014; Accepted 24 February 2015

Academic Editor: Orazio Schillaci

Copyright (C) 2015 Anish A. Patel et al. This is an open access article distributed under the Creative Commons Attribution License, which permits unrestricted use, distribution, and reproduction in any medium, provided the original work is properly cited.

Bone is a dynamic organ of the endoskeleton, playing an important role in structural integrity, mineral reservoirs, blood production, coagulation, and immunity. Metabolic bone disease encompasses a broad spectrum of inherited and acquired disorders that disrupt the normal homeostasis of bone formation and resorption. For patients affected by these processes, radiologic imaging plays a central role in diagnosis, monitoring treatment, and risk stratification. Radiologists should be familiar with the diseases, intimately aware of the imaging findings, and possessive of multimodality expertise to wisely guide the best practice of medicine. The purpose of this paper is to review the imaging features and characteristics of the most common types of metabolic bone disease with highlights of clinically relevant information so that readers can better generate appropriate differential diagnoses and recommendations. For this review, a thorough literature search for the most up-to-date information was performed on several key types of metabolic bone disease: osteoporosis, osteomalacia, rickets, scurvy, renal osteodystrophy, hyperparathyroidism, Paget's disease, osteogenesis imperfecta, acromegaly, and osteopetrosis. Although they all affect the bone, these diseases have both shared characteristic features that can be discerned through imaging.

\section{Introduction}

Bone is composed of extracellular and cellular components and undergoes constant remodeling. The complex regulation of calcium and phosphate involves the intestines, kidneys, hormones, and vitamin D. Metabolic bone disease is a diverse class of acquired and inherited diseases resulting in increased bone matrix, decreased bone matrix, or abnormal bone mineralization. On imaging, the diseases generally result in increased bone density (osteosclerosis) or decreased bone density (osteopenia), which in turn can cause deformity and debilitation through remodeled or severely weakened bone. Because patients at risk for these diseases benefit from early diagnosis and periodic surveillance, a comprehensive understanding of relevant radiological findings is necessary for appropriate prevention and management. In this paper, we discuss the more commonly encountered metabolic bone diseases and, specifically, we review the multimodality imaging features and trends.

\section{Osteoporosis}

2.1. Introduction. As the most common of the metabolic diseases of the bone, osteoporosis affects one in two women and one in five men over the age of 50 in the western world [1]. Generalized osteoporosis can be categorized into two general types: primary and secondary. Primary osteoporosis can be further categorized into type I (postmenopausal) or type II (senile). Type I osteoporosis predominantly affects women between the ages of 50 and 65 and is a result of estrogen deficiency causing accelerated trabecular bone resorption. This subset of osteoporosis tends to involve the spine and wrist. In contrast, type II (senile) osteoporosis affects both trabecular and cortical bone, resulting in characteristic fractures of the hip, proximal humerus, tibia, and pelvis [2].

The clinical and radiological presentation of osteoporosis is oftentimes similar to other metabolic bone diseases, which are discussed later in detail. However, malignant processes may also result in a similar clinical picture, and it is important 


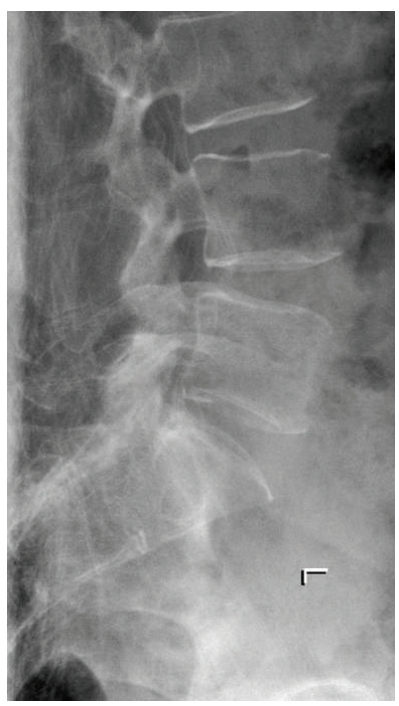

(a)

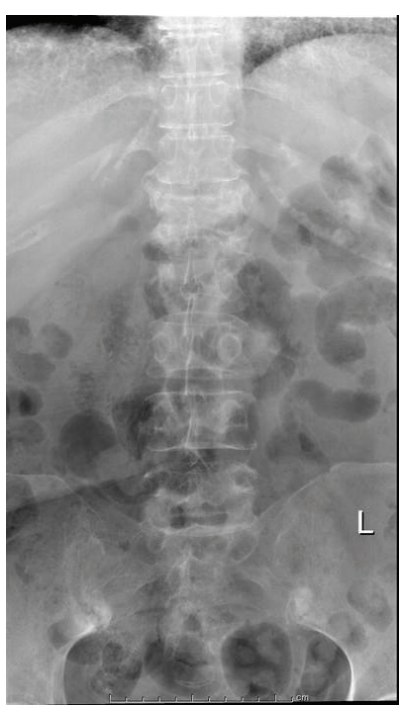

(b)

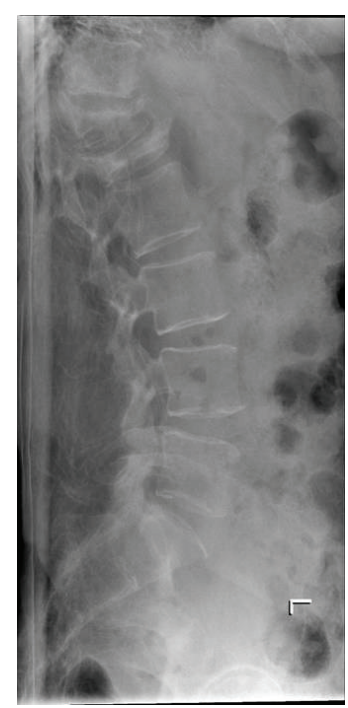

(c)

Figure 1: Osteoporosis. Multilevel lumbar spine cortical thinning and lack of trabeculation result in "picture framing" or "empty box" appearance on coned down lateral view of the lumbar spine (a). Fragility compression fractures of T12 and L1 vertebral bodies with greater than $50 \%$ height loss AP (b) and lateral view radiographs (c).

to identify the subtle differences. In general, red flags for a malignant fracture include a soft tissue mass and osseous destruction, as well as a location above T7 in the spine, especially in the posterior portion of the vertebral body. Whereas a concave posterior vertebral border is more likely benign, a convex posterior border is more suggestive of malignancy.

2.2. Radiography. Even with the newest advances in quantitative imaging techniques, conventional radiography is still the most commonly used modality when encountering demineralization, although it usually detects pathology only after $30 \%$ of bone has been lost [3]. In general, hallmark features of osteoporosis on radiography include thinned cortices, endosteal reabsorption, and a decrease in the number of trabeculae.

Certain bones of the body are preferentially affected by osteoporosis due to relatively larger proportions of trabecular bone. With conventional radiography, these changes are most evident in the axial skeleton along with the ends of long and trabecular bones of the juxtaarticular appendicular skeleton [4].

As the result of osseous resorption in the cortex, cortical thinning occurs and typically involves the endosteal envelope, causing a scalloped inner margin of the cortex. This endosteal scalloping is not specific to osteoporosis and may occur in conditions with high bone turnover, such as hyperparathyroidism or reflex sympathetic dystrophy syndrome. The appearance of intracortical tunneling and subperiosteal resorption is more specific to these rapid bone turnover states that are less apparent with low turnover states such as senile osteoporosis [5].

In the axial skeleton, cortical thinning results in the welldemarcated outline of the vertebral body, giving rise to a "picture frame" or "empty box" appearance (Figure 1) [6].
Another feature of spinal osteoporosis is the verticalization of trabeculae, which is an early sign of the disease that results from the rarefaction of the horizontal trabeculae, leaving the vertical trabeculae relatively accentuated [4].

A hallmark manifestation of osteoporosis is vertebral compression fracture (Figures 2 and 3). A history of vertebral fracture due to osteoporosis increases an individual's risk of subsequent vertebral fractures by five and hip fractures by two. $20 \%$ of these fractures occur within 12 months of the first. Up to $50 \%$ of vertebral fractures are asymptomatic and are found incidentally on imaging studies performed for unrelated reasons [7]. A true vertebral fracture can be diagnosed with anterior vertebral body height loss of greater than $4 \mathrm{~mm}$ since the posterior height of the thoracic vertebrae is normally greater than the anterior height by $1-3 \mathrm{~mm}$ [8]. An alternative vertebral fraction definition consists of a height loss of more than $20 \%$ with an areal reduction of more than $10-20 \%$ [9]. When diagnosing osteoporotic vertebral fractures on radiography, it should be noted that they are rarely associated with an apparent breach of the cortex or significant callus formation, unlike with fractures of long bones [10]. The best techniques by which to view vertebral fractures are lateral spinal radiographs and sagittal reformations from multidetector spiral CT since these modalities allow the transverse orientation of the vertebral endplates [1].

Quantitative vertebral morphometry can be used as an objective way to measure vertebral body heights by tagging landmarks for each vertebra. The most popular of these techniques is six-point digitization, which marks out the four corners of each vertebra from T4 to L4 or L5 with additional points in the middle of the upper and lower end-plates. Software is then used to analyze any anomalous geometry. However, quantitative morphometry cannot be used to identify fractures resulting from vertebral deformities 


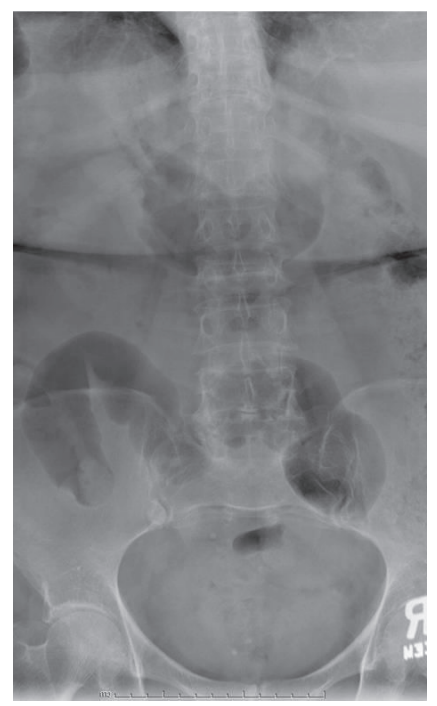

(a)

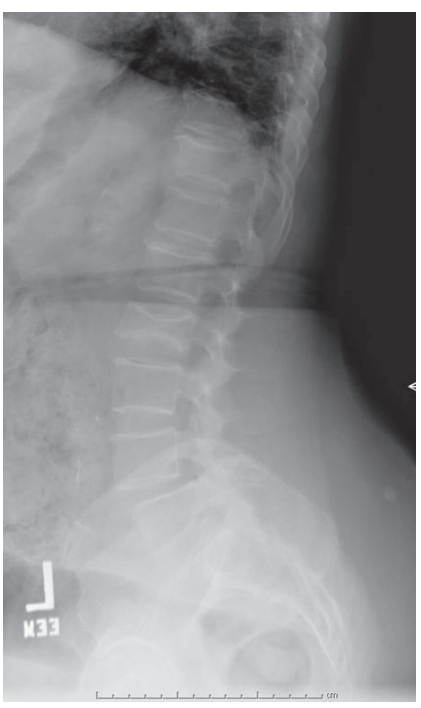

(b)

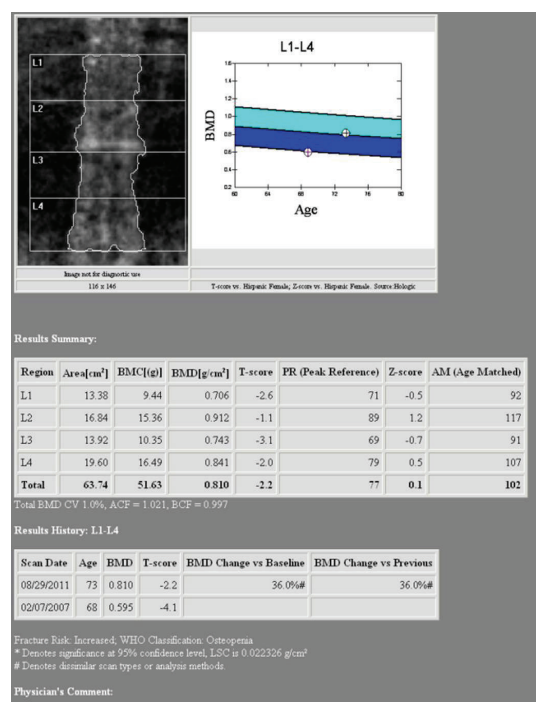

(c)

FIGURE 2: Osteoporosis. Compression deformity of L2 on AP (a) and lateral view (b) radiographs results in falsely increased bone densitometry values on the submitted bone densitometry (c); the L2 level should be excluded and the bone densitometry reanalyzed.

due to pathology such as degenerative spine or disk disease [2].

Osteoporotic pathology in the appendicular skeleton involves the ends of long and tubular bones, especially in the hand, proximal femur, and calcaneus. A semiquantitative measure for grading osteoporosis in the hand is the corticomedullary index, which is based on the evaluation of the cortical thickness at the second metacarpal bone [2].

Radiogrammetry is a quantitative method for measuring the skeleton that was first developed in the 1960s and has returned in 2000 with the advance of digital X-ray radiogrammetry (DXR), which automatically detects the bone edges of the shafts of metacarpals 2 through 4 . Due to the greater requirements for precision with imaging of the hand, DXR was developed to automate the calculation of basic geometric measurements of the metacarpal bones in order to estimate bone mineral density. The technique is highly reproducible, predictive of future fractures, and useful in identifying patients at risk who may benefit from further dual energy X-ray absorptiometry (DEXA) evaluation [11]. Osteoporosis of the appendicular skeleton can also be assessed by rating the integrity of the trabecular pattern within the proximal femur or the calcaneus [12]. Because DXR can detect between 0.0012 and $0.0028 \mathrm{~g} / \mathrm{cm}^{2}$ of difference, it is useful in following changes in bone mineral density (BMD) over short periods of time [11]. DXR is also especially useful in tracking the effectiveness of bisphosphonate therapy [13]. As of now, however, the technique remains primarily as a research tool rather than a central player in the clinical diagnosis of osteoporosis.

2.3. DEXA. The World Health Organization's (WHO) definitions for the threshold levels in diagnosing osteopenia and osteoporosis were introduced in 1994 and are currently the standard for the use of bone densitometry in diagnosing and classifying demineralization. DEXA measurements are provided using bone mineral content (in grams) and projected area of the measured site (in square centimeters). Bone mineral density (BMD) is thus calculated by dividing the mineral content by the area and is expressed in terms of standard deviation by comparison to the mean BMD of young adults ( $T$ score) or of age-matched patients of the same sex ( $Z$ score). BMD is classified by the WHO based on $T$ score with categories such as normal $(\geq-1.0)$, osteopenic $(<-1.0$ but $>-2.5)$, osteoporotic $(\leq-2.5)$, and severely osteoporotic $(\leq-2.5$ with a fragility fracture). $T$ scores are adjusted for patients on antiosteoporotic drugs as well as osteoporosisinducing drugs. Patients on glucocorticoids have a $T$ score cutoff of -1.5 while patients on aromatase inhibitors have a cutoff of $-2.0[14,15]$.

DEXA has many advantages including its rapidity, low cost, and lower radiation risks, but it does have some limitations as a two-dimensional technique. For example, DEXA does not distinguish between cortical and trabecular bone or changes due to bone geometry and can also result in the overestimation of density in larger bones and the opposite for smaller bones [2]. Since DEXA measures BMD in terms of area, it should be noted that areal BMD accounts for only $60-70 \%$ of bone strength [16]. Furthermore, it can take DEXA scanners more than 2 years to detect a statistically significant change in areal BMD [17]. The tendency for DEXA to overestimate areal BMD in large bones is especially problematic in growing children. DEXA also tends to overestimate areal BMD if any high-density object is in the path of the beam, including arterial calcification, fractures, metal implants, and degenerative vertebral body endplate sclerosis. Conversely, laminectomy results in underestimation of BMD. Children under 19 years of age have not yet reached peak bone mass and can only provide reliable data via $Z$ scores, not $T$ scores [16]. 


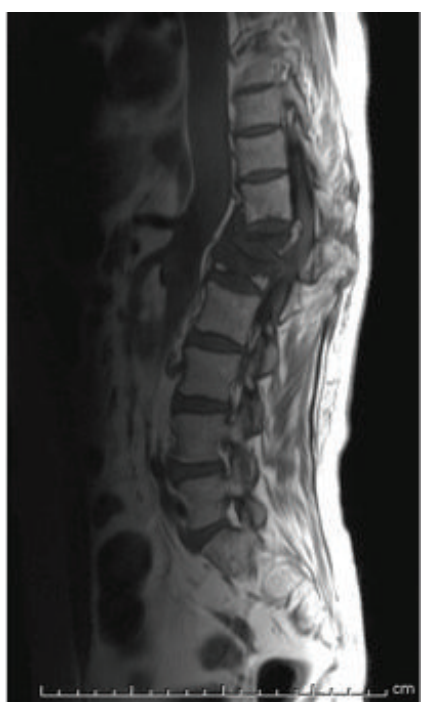

(a)

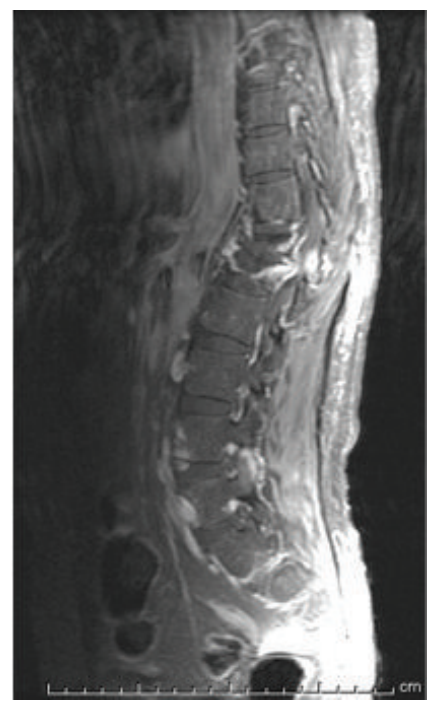

(c)

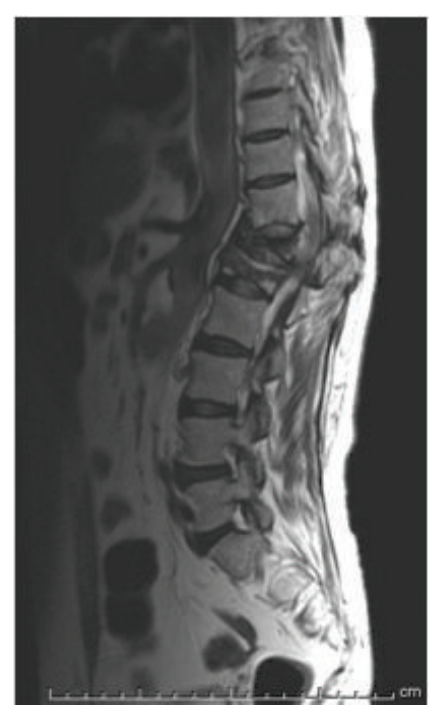

(b)

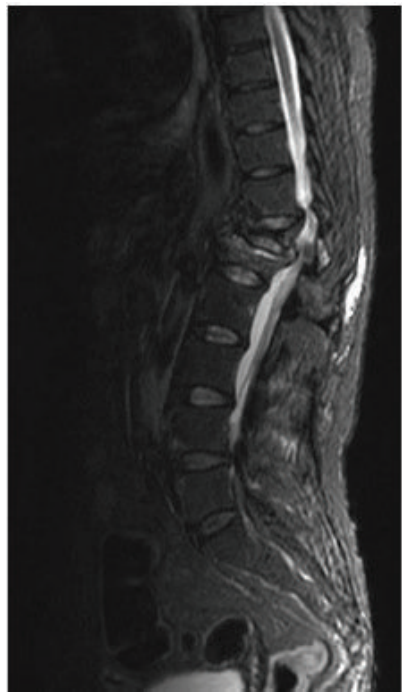

(d)

FIGURE 3: Osteoporosis. On sagittal T1 (a), T2 (b), T1 after contrast (c), and STIR sequences (d), T1 hypointense and STIR hyperintense, enhancing acute compression fractures of T12 and L1 vertebral bodies. Retropulsion of fragments result in moderate spinal canal stenosis.

Other errors that often occur with interpretation of DEXA images relate to improper positioning, numbering the vertebrae, and detection of bone edges. Anatomic artifacts resulting from degenerative disk disease, compression fractures, postsurgical defects, and overlying atherosclerotic calcifications may also be present as common comorbidities in this aging patient population. Implantable devices such as stents as well as external objects such as buttons can also interfere with interpretation. Finally, it is important to note that the results from different DEXA scanners are not interchangeable due to the use of different algorithms and analytic techniques by various manufacturers [18-20].

Portable DEXA scanners are increasing in availability and can be used to analyze BMD in peripheral sites such as the distal radius and calcaneus. The WHO criterion for diagnosing osteoporosis ( $T$ score $\leq-2.5)$ can be used for the forearm but is not applicable to the calcaneus. The definitive boundaries have not been determined, although scores between -1.0 and -1.5 have been suggested [21].

A significant advantage of DEXA is its unique ability to be used with FRAX (Fracture Risk Assessment Tool), which was introduced in 2008 and is used to identify patients at higher risk for fractures as well as estimate their 10-year probability of a major osteoporotic fracture. In addition to BMD, FRAX utilizes patient demographic data (age, sex, race, and body habitus) in the context of risk factors such as history of previous fractures and alcohol use. The algorithm also incorporates manufacturer of the DEXA scanner as part of its analysis [22].

A growing use for DEXA is with vertebral fracture assessment (VFA), which differs from conventional spinal radiography in that the entire spine is visualized on a single 
lateral image rather than two separate lateral projections. VFA not only requires less ionizing radiation but also avoids the optical distortion of vertebral endplates often seen with radiography [23].

The technique is gaining in popularity and guidelines have already been established for its use, although there is currently little data supporting the application for children. An interesting potential adjunct use for VFA is the grading of abdominal aortic calcification, a risk factor associated with cardiovascular disease in elderly women. Thus, VFA allows for this population to undergo evaluation for cardiovascular disease during bone densitometry [24]. Trabecular bone scoring has also emerged in the past decade as a way of measuring trabecular structure, but its reliability and usefulness have yet to be determined in the clinical setting [25].

2.4. Quantitative CT. Another technique that can estimate BMD is quantitative CT, which is different from DEXA in that it provides separate estimates of trabecular and cortical density to assess true volumetric density with macroarchitecture rather than a two-dimensional recreation [26]. This capacity is significant when considering that trabecular bone is eight times more metabolically active than cortical bone and thus more sensitive to change [1].

Because quantitative $\mathrm{CT}$ can distinguish trabecular versus cortical bone, it is more sensitive than DEXA in predicting vertebral fractures and tracking chronic bone loss, especially in postmenopausal women. It is also particularly useful for assessing corticosteroid-induced osteoporosis and treatment with parathyroid hormone, since these diseases tend to preferentially affect trabecular bone [13].

Although BMD values from DEXA can be falsely elevated from pathology such as degenerative joint disease and aortic calcification, this is not true for quantitative CT due to its superior spatial resolution [27].

Although literature regarding fracture prediction for QCT is limited compared to that for DEXA, the number of studies is increasing as QCT becomes more popular. QCT is able to better predict spinal fracture by measuring vertebral BMD more accurately compared to areal BMD utilized by DEXA [28]. It is also a good tool for analyzing components and factors regarding hip fracture, but the radiation dose to the gonads with these studies is concerning. It may also be difficult to scan children using QCT since the slow scanacquisition time can result in many movement artifacts [16].

Accurate measurement with quantitative $\mathrm{CT}$ can also be disrupted by the presence of marrow changes within the bone due to an alteration in medullary attenuation. Although the modality tends to become less accurate over time as a result of age-related changes in vertebral bone marrow, this error can be corrected using reference databases and is not usually clinical relevant [29]. Another limitation to QCT's low spatial resolution is that it has difficulty measuring thin bone cortices [30]. Furthermore, due to the complexity of the hip and femoral region, quantitative CT is only used to assess spinal volumetric BMD. Some of these limitations can be overcome by the use of peripheral quantitative CT, which can make separate assessments of cortical versus trabecular bone as well allow analysis of bone geometry at multiple appendicular sites [2].

It is worthwhile to note that the results from QCT cannot be used for $T$ score calculations as defined by the WHO, nor can QCT be used for the FRAX algorithm [1].

Other important restrictions of quantitative CT compared to DEXA include increased radiation dose, high cost, disruption to other diagnostic CT workflow, and space requirements. Compared to conventional $\mathrm{CT}$, however, the dose is decreased in quantitative CT. Because quantitative measurements rather than high-precision images are desired in QCT, the radiation dose can be minimized to around $100 \mu \mathrm{Sv}$ compared to conventional CT, which has doses from 2500 to $4500 \mu \mathrm{Sv}$ [16].

2.5. Quantitative Ultrasound. Quantitative ultrasound was introduced nearly 30 years ago as a cheaper, smaller, faster, safer, and more portable alternative DEXA scanners. While diagnostic ultrasound uses wavelengths of $2-10 \mathrm{MHz}$, quantitative US stays within a range of less than $1 \mathrm{kHz}$ [1]. It is wellknown for its quickness and low risks compared to the other modalities, but it lacks comparable sensitivity. Although it can be used to measure quantitative parameters and assess tissue properties, quantitative US is inadequate for long-term monitoring of osteoporosis and best serves as a screening tool prior to DEXA evaluation [31]. The calcaneus and phalangeal metaphysis may yield the highest benefit when utilizing quantitative US due to their high proportion of trabecular bone [32]. It should be noted that, as of yet, there are no current guidelines for the standardization of these US devices in terms of reliability among manufacturers. Another difficulty is that the WHO criteria cannot be used with quantitative US, relegating the technique as more of a supplemental rather than standalone tool for diagnosing osteoporosis [2]. Although quantitative US cannot utilize the WHO definition to diagnose osteoporosis nor monitor the effectiveness of therapy, calcaneal quantitative US can help predict hip and other osteoporotic fractures in postmenopausal women and elderly men as well as central DEXA scans [33].

2.6. New Advances. Micro-CT is a newer technique that can resolve up to $6 \mu \mathrm{m}$ for enhanced visualization of trabecular structures. After three-dimensional reconstruction, software can be used to calculate parameters such as bone surfacevolume ratio and trabecular parameters like volume, number, sparsity, thickness, and orientation. MR imaging can be used with similar precision except that it cannot directly visualize the trabecular network and must instead be extrapolated as part of a signal void within the fatty bone marrow. Although it is not commonly used clinically and there are no current guidelines, MR imaging shows potential as a technique for monitoring treatment effects, especially as higher field strengths become more widespread [2]. Both of these highresolution techniques are used on peripheral sites like the radius or tibia but can be technically challenging with regards to fastidious positioning and susceptibility to movement artifacts. These difficulties combined with the availability of these machines and utilization for other diagnostic imaging 


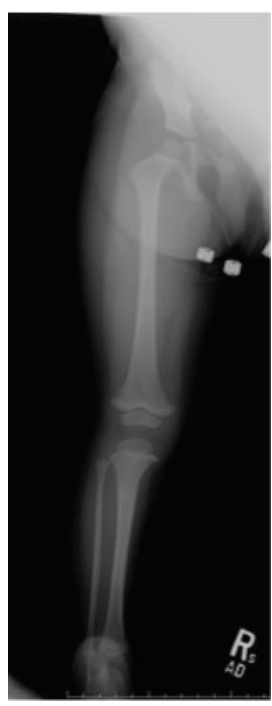

(a)

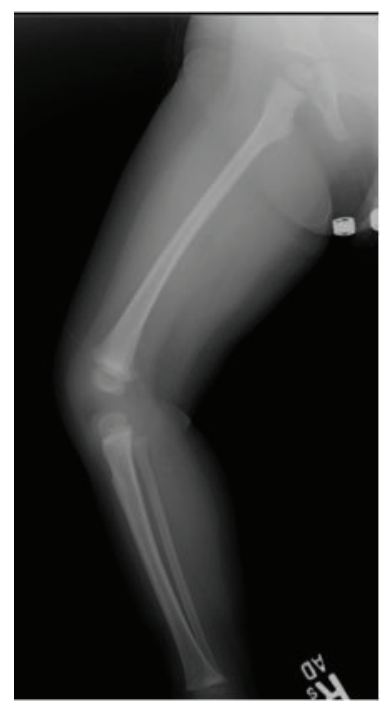

(b)

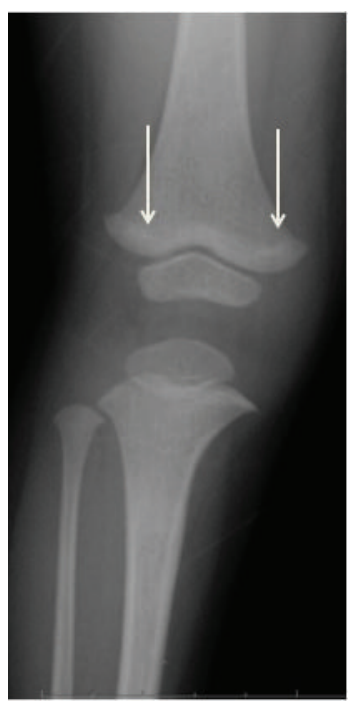

(c)

Figure 4: Rickets. Dense metaphyseal bands (arrows), most prominent at the distal femur on AP (a), lateral (b), and magnified (c) views of the right lower extremity in a 19-month-old female undergoing treatment for vitamin D deficiency.

and intervention have kept them as research tools for the time being [34].

\section{Osteomalacia/Rickets}

Incomplete mineralization due to lack of calcium salts in osteoid manifests as osteomalacia in adults and rickets in children. While there are various causes such as gastrointestinal absorptive abnormalities and renal tubular lesions, the central abnormality involves calcium, phosphorous, or vitamin D metabolism (Figure 4). General radiographic signs are nonspecific and include decrease in bone density, loss of cortical definition, and coarsening of the trabecular pattern. Commonly noted deformities include protrusio acetabuli, kyphoscoliosis, and increased endplate concavity in the spine [35]. Bony deformities such as bowing can be bilateral and symmetric and are predominantly seen in weight-bearing bones (Figure 5). Looser zones or pseudofractures are insufficiency fractures that appear as linear radiolucent bands perpendicular to the long axis of the bone and are most frequently seen in pubic and ischial rami, medial femoral necks, ribs, scapulae, and long bones (Figures 6 and 7) [35, 36]. They are classically at the concave (compressive) side of a bowing deformity.

\section{Scurvy}

4.1. General. Scurvy, also known as Barlow disease, is a manifestation of vitamin $\mathrm{C}$ (ascorbic acid) deficiency and is predominantly a disease of the pediatric age group that presents in the first 6-24 months [37]. The adult incidence of scurvy is rare and is primarily due to severe dietary deficiency [38]. Lack of vitamin C results in abnormal collagen formation that results in a variety of clinical signs and symptoms: irritability, defective dentine formation, hemorrhagic tendency, tenderness, and weakness of lower limbs resulting in pseudoparalysis. Musculoskeletal manifestations occur in $80 \%$ of patients with scurvy and radiologic findings are characteristic [38].

4.2. Radiographic Manifestations. Radiographic features are most commonly seen at the site of rapid bone growth and include the distal femur, proximal and distal tibia and fibula, radius and ulna, and humerus. Enlargement of the sternal end of the ribs results in a "scorbutic" rosary. Ground glass osteoporosis affecting both the trabecular and cortical bone is highly characteristic $[38,39]$. The zone of provisional calcification shows increased density and is known as the white line of Frankel. The Trummerfeld zone is the site of subepiphyseal infraction and seen as a radiolucent zone adjacent to the white line of Frankel $[39,40]$. Due to subepiphyseal location, fractures that occur in the Trummerfeld zone heal without affecting bone growth $[39,40]$. Other metaphyseal findings include lateral Pelkan spurs that are seen projecting perpendicular to the shaft axis. "Corner sign" occurs due to continued comminution resulting in mushrooming or cupping of epiphysis and can also be seen in syphilis and rickets [39]. Thickening of zone of provisional calcification with sparse trabeculation of the adjacent epiphysis results in a sclerotic epiphyseal ring, also known as Wimberger's ring $[39,40]$. Subperiosteal hemorrhage is a subtle finding that appears as a soft tissue density adjacent to the cortical bone. However, with treatment, calcification of the elevated periosteum becomes apparent and is an early sign of healing $[39,40]$. With continued treatment most radiological signs disappear; however, Frankel's line remains as an indicator of prior vitamin $\mathrm{C}$ deficiency. 


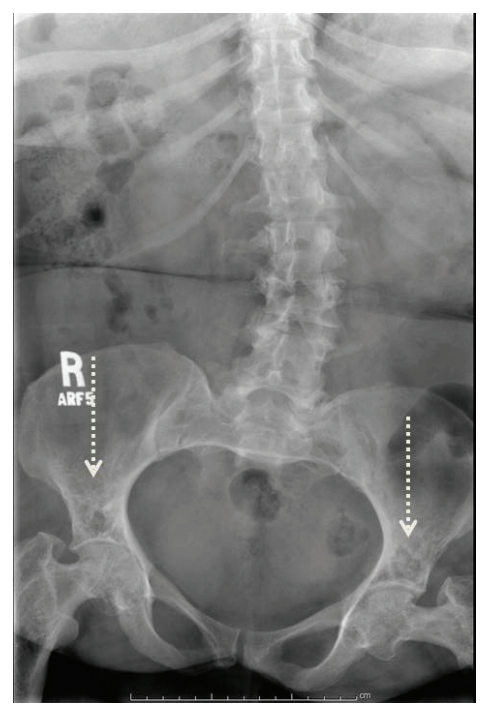

(a)

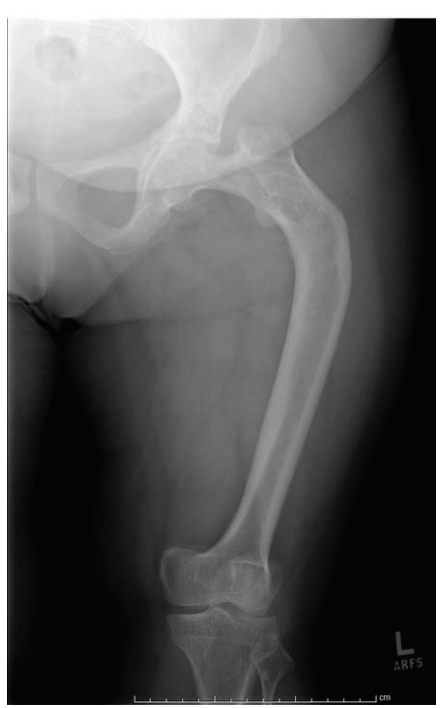

(b)

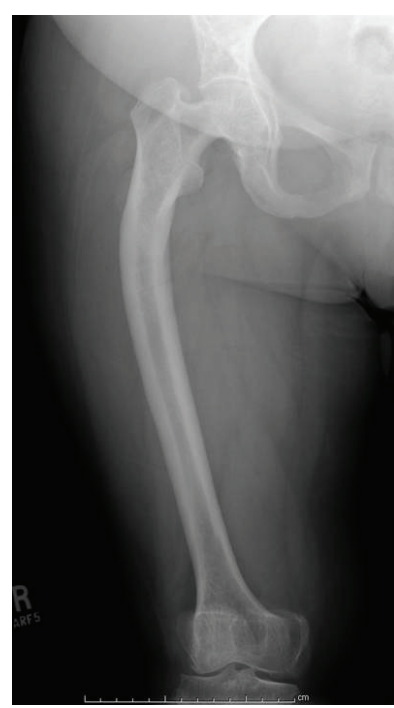

(c)

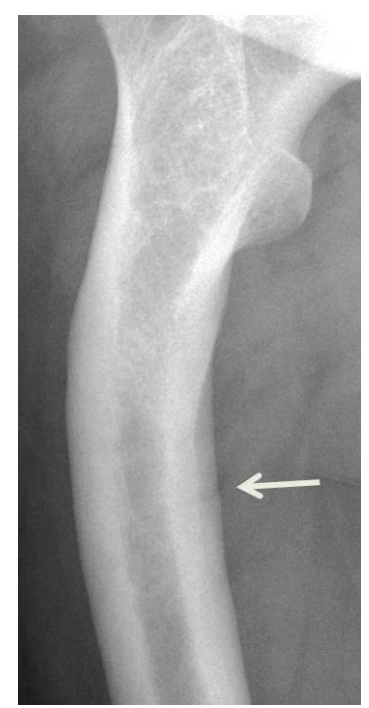

(d)

FIgURE 5: Osteomalacia. A 51-year-old female with levoscoliosis and heterogeneous density of the ilia adjacent to the acetabula (dotted arrows) likely from abnormal mineralization on AP view of the lumbar spine (a). Bowing deformities (Shepherd's crook deformity) on AP views of the femora ( $b$ and c) and magnified view of the right proximal femur. (d) Subtle lucency along the concave medial border of the right proximal femur (white arrow) represents a Looser zone.

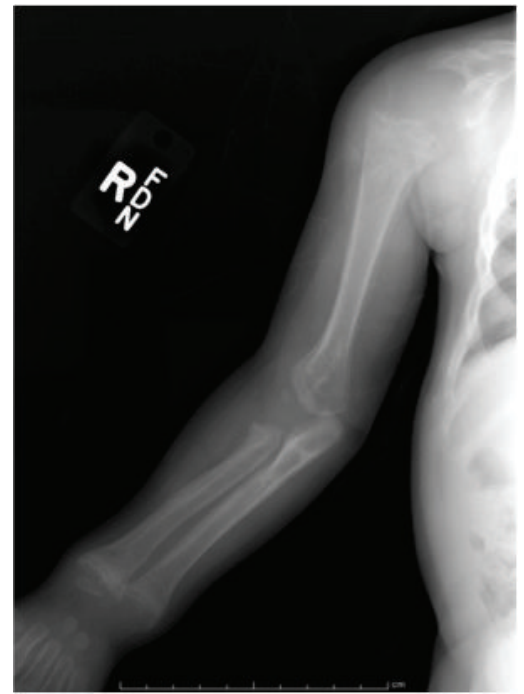

(a)

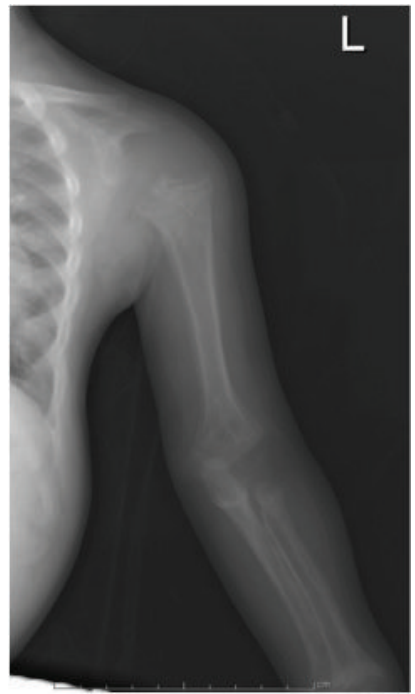

(b)

FIGURE 6: Rickets. Bilateral humeral radiographs in a 25-month-old male demonstrate fraying and increased lucency of bilateral proximal humeral and right distal radial physes. Polyostotic periostitis and generalized demineralization.

\section{Renal Osteodystrophy/Hyperparathyroidism}

5.1. General. Renal osteodystrophy refers to a spectrum of radiographic musculoskeletal abnormalities in the setting of chronic renal failure (CRF). CRF causes secondary hyperparathyroidism, which predominates the radiographic findings; therefore, there is considerable overlap of musculoskeletal findings in these entities. In addition, renal osteodystrophy causes osteomalacia and other treatment related manifestations. In this review, a brief overview of renal osteodystrophy and associated findings along with changes seen in hyperparathyroidism are presented.

Parathyroid hormone plays a crucial role in regulation of serum calcium and phosphate through alteration in osteoclastic activity, intestinal absorption and renal absorption and excretion of calcium and phosphate. Excessive secretion of parathyroid hormone (PTH) results in a spectrum of musculoskeletal, specifically osseous manifestations that most commonly lead to osteomalacia and osteoporosis. 


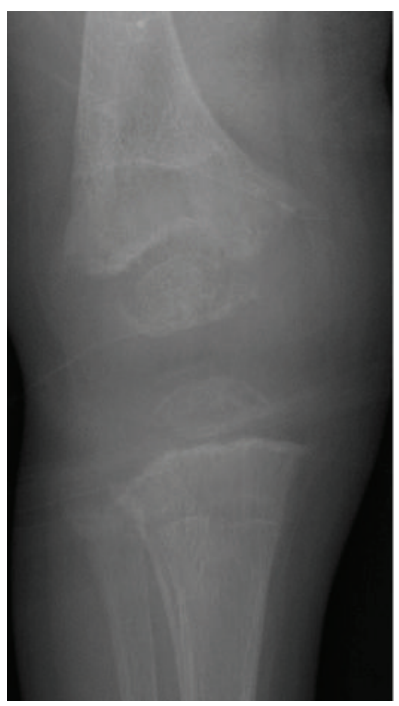

(a)

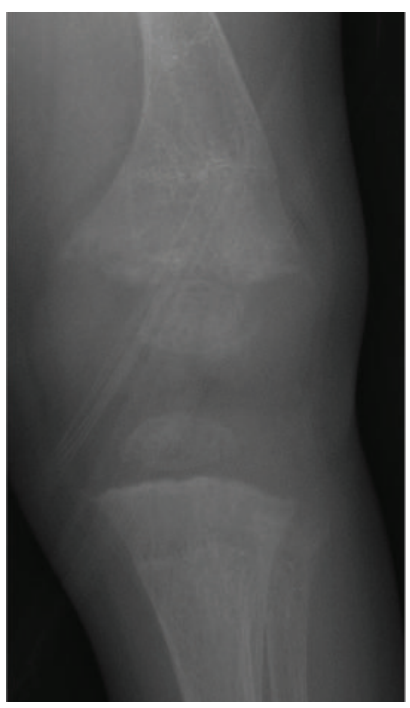

(b)

FIGURE 7: Rickets. Bilateral knee radiographs demonstrate widening of the physis with prominent metaphyseal fraying and cupping along with polyostotic subperiosteal lucencies.

Overproduction of parathyroid hormone may be classified into primary, secondary, and tertiary causes. Primary hyperparathyroidism results from an overproduction of PTH due to adenoma (90\%), followed by parathyroid hyperplasia and parathyroid carcinoma. Hypocalcemia in chronic renal failure or due to intestinal malabsorption results in secondary hyperparathyroidism. Tertiary hyperparathyroidism occurs when parathyroid gland acts autonomously and independently of serum calcium in the setting of dialysis.

5.2. Radiographic Features. In the past, a "metabolic bone survey" that included direct magnification radiography, mammographic techniques, and fine-detail radiography techniques were used for early diagnosis of subtle osseous abnormalities. With advances in digital radiography, routine hand radiographs are now considered the most sensitive and cost effective method for early detection [35].

Increased osteoclastic activity results in range of manifestations and the most common nonspecific feature is generalized demineralization. Bony resorption is more specific for hyperparathyroidism and involves periosteal, intracortical (within Haversian system and Volkmann's canal), subchondral, trabecular, and subligamentous surfaces.

Subperiosteal resorption is the earliest finding, virtually pathognomonic of hyperparathyroidism, and is most commonly seen as fraying and lace-like appearance of external surface of bone along the radial aspects of middle phalanges of second and third digits and phalangeal tufts [35]. Other sites of subperiosteal resorption include the distal end of the clavicles, medial humerus and tibia, femoral neck, and distal ulna.

Intracortical tunneling is a hallmark of rapid bone turnover and manifests as scalloping along the inner cortical surface, most notable in the second metacarpal, as subtle longitudinal striations. Over time, there is loss of cortical definition and corticomedullary differentiation [35].

Subchondral resorption is polyarticular and leads to collapse of cortical bone that results in initial "pseudowidening" of joint space, along the iliac side of the sacroiliac joint and the clavicular side of the acromioclavicular joint and symphysis pubis. With continued erosion, there is damage and collapse of articular cartilage and degenerative changes ensue. Subchondral resorption can sometimes be confused with erosions in an inflammatory arthropathy such as rheumatoid arthritis.

Trabecular resorption is most commonly noted in the calvarium and is seen as spotty deossification, loss of a sharp trabecular pattern, and loss of distinction between inner and outer tables resulting in as a ground glass appearance or "salt and pepper" calvarium (Figures 8 and 9) [36, 41]. Subligamentous and subtendinous changes are nonspecific and can be frequently noted in the inferior calcaneus, coracoclavicular ligaments, greater and lesser trochanters, anterior inferior iliac spine, and humeral and ischial tuberosities.

Brown tumors or osteoclastomas are cyst-like, well circumscribed lytic lesions that commonly occur in the jaw, pelvis, and metaphyses of long bones (Figure 10). They may be eccentric or central, and associated findings include endosteal scalloping and lack of reactive bone formation distinguishing it from an aggressive entity. As brown tumors heal with treatment, they may have calcifications, dense sclerotic appearance, or persist as a lytic lesion [36]. Histologically, they are composed of highly vascular fibrous tissue (osteitis fibrosa cystica) containing giant cells that often hemorrhage (and imparts a brown color) and undergo liquefactive necrosis giving the cystic appearance. In the past, brown tumors were thought to be specific for primary hyperparathyroidism but can also be seen with secondary hyperparathyroidism due to an overall greater prevalence. 


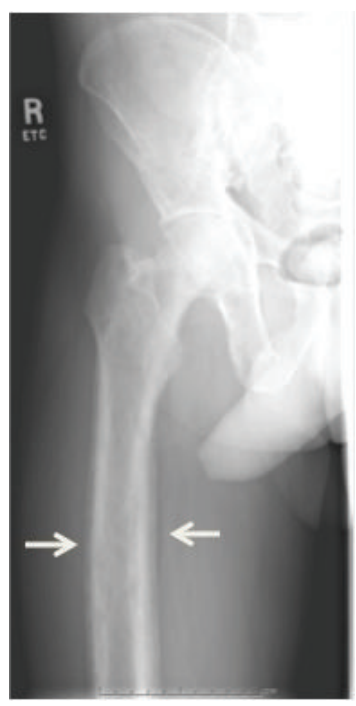

(a)

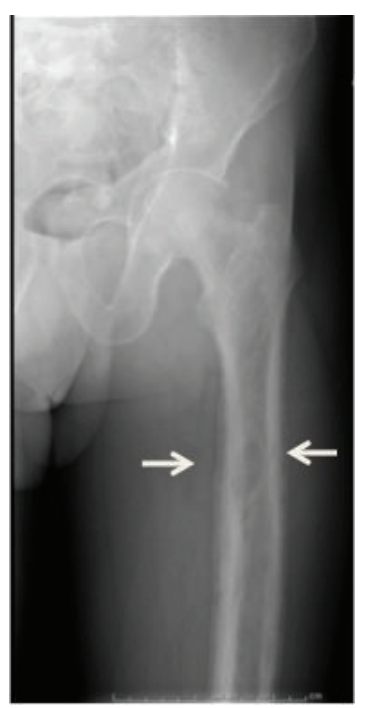

(b)

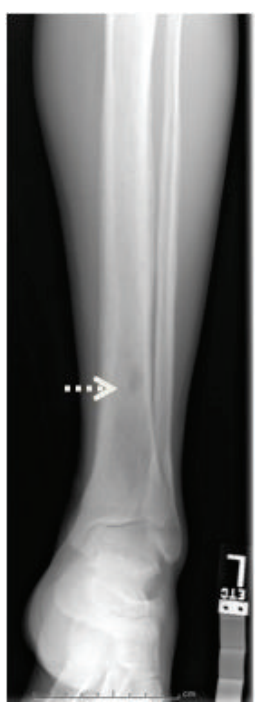

(c)

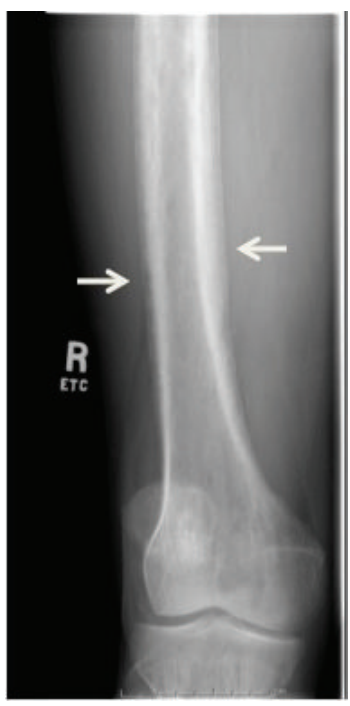

(d)

FiguRE 8: Renal osteodystrophy. A 33-year-old male with end-stage renal disease and tertiary hyperparathyroidism with thin periosteal reaction and cortical tunneling on bilateral hip ( $\mathrm{a}$ and b), left tibial (c), and right distal femoral (d) radiographs. Focal lucent lesion (dashed arrow) in the left tibia (c) likely represents a brown tumor.

Osteosclerosis is most commonly seen in secondary hyperparathyroidism, especially during the healing phase and predominantly involves the axial skeleton (due to greater amount of cancellous bone) and less frequently the metaphyses and epiphyses of appendicular skeleton (Figure 11). Exact mechanism of osteosclerosis is unclear and is thought to involve PTH stimulated osteoblastic activity either after treatment or as a counter response to resorption where osteoblasts produce excessive nonhydroxyapatite osteoid [41, 42]. Excess accumulation of osteoid appears more opaque than normal bone and results in the classic "rugger-jersey" spine, alternating sclerotic and lucent bands along the inferior and superior endplates of vertebral bodies similar to the stripes on an English rugby shirt [42-44] (Figure 12). Osteosclerosis may be the sole manifestation of renal osteodystrophy and may regress postrenal transplantation [36].

Soft tissue and vascular calcifications are also seen more frequently in secondary hyperparathyroidism from chronic renal disease (Figures 13 and 14). Metastatic deposition of calcium hydroxyapatite or amorphous calcium phosphate increases as the calcium-phosphorus product increases. Recently, more complex mechanisms including changes in endogenous calcification inhibitors, deficient clearance of calcified debris, and effects of vitamins $\mathrm{K}$ and $\mathrm{D}$ have also been implicated in determining extraosseous calcification [45].

While visceral calcifications in heart, lung, and stomach may not be radiographically detectable, periarticular, cartilaginous, and vascular calcifications in the tunica media are frequently seen especially in chronic kidney disease. Periarticular calcifications occur about the large joints (hip, shoulder, elbow, and knee), wrists, ankles, and phalangeal joints. Calcifications can be multifocal and symmetric and appear as discrete, cloud-like densities that may extend to the adjacent joint [36].

\section{Dialysis}

Patients who progress to end-stage renal disease and are placed on dialysis present with a mixed spectrum of manifestations, where some effects of chronic kidney disease improve, while others persist [46-48].

Aluminum intoxication is a commonly noted condition in patients managed with dialysis and is secondary to aluminum in the dialysate or due to oral ingestion of aluminum hydroxide as a phosphate binder. Radiographic findings are nonspecific and include osteomalacia, fractures of the ribs, cervical spine, hip, and pelvis [49]. Amyloidosis causes extraosseous (tendon and ligament deposition) and osseous deposition that result in periarticular erosive osteoarthropathy, destructive spondyloarthropathy, and carpal tunnel syndrome [50, 51]. Erosive arthropathy has been described of the small joints and mimics degenerative osteoarthritis [52]. Ligamentous laxity with superimposed amyloid deposition and hyperparathyroidism results in destructive spondyloarthropathy, most commonly in the cervical and lumbar spine $[53,54]$. Osteonecrosis is another serious complication with a multifactorial etiology that commonly involves the femoral and humeral head and condyles [55]. Tendon rupture and musculoskeletal infections are also commonly seen as dialysis or posttransplant related complications $[56,57]$.

\section{Paget's Disease}

7.1. Introduction. In brief, Paget's disease is caused by defective osteoclastic bone breakdown with compensatory osteoblastic bone formation, resulting in irregular bone remodeling with a disorganized, structurally weak pattern of woven and lamellar bone [13]. Asymmetrical polyostotic involvement is the most common pattern of bone involvement, especially within the axial skeleton, although 


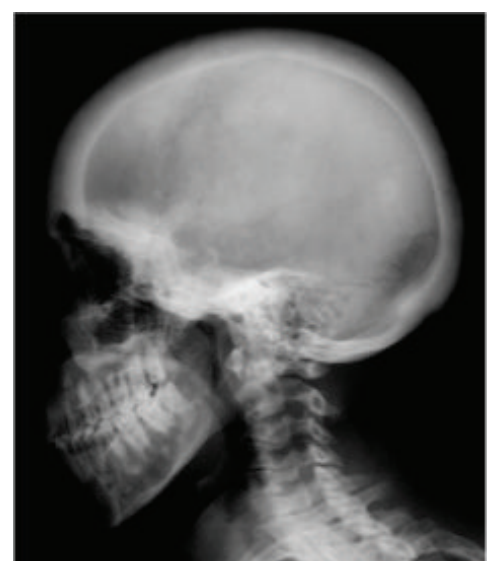

(a)

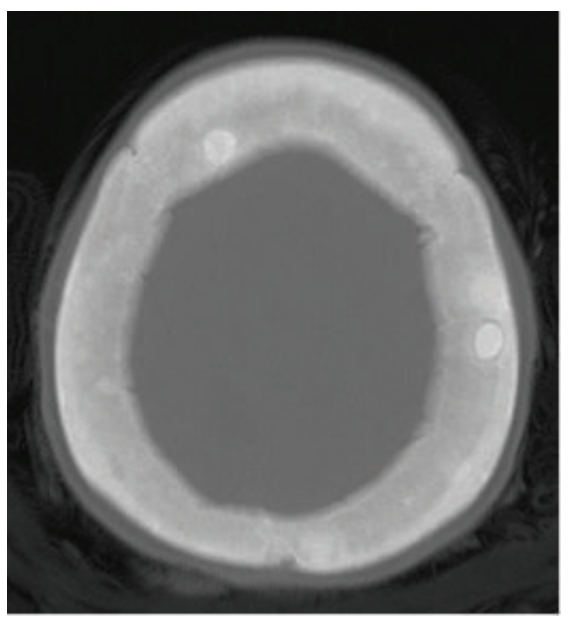

(c)

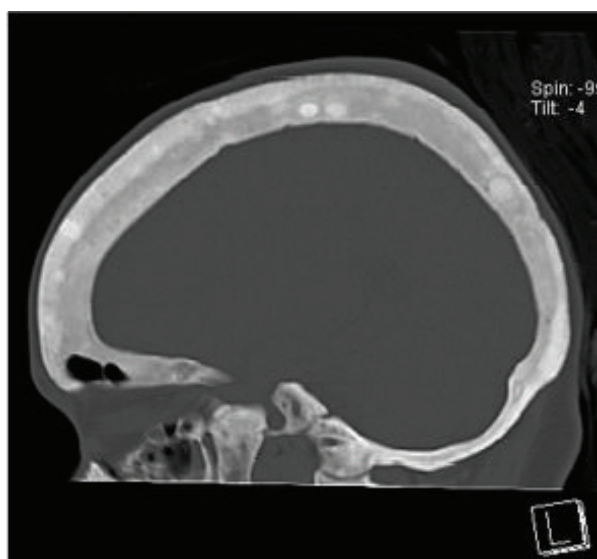

(b)

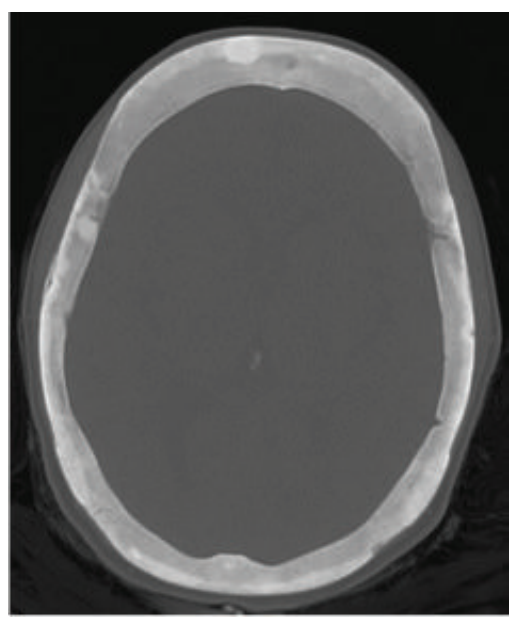

(d)

FIGURE 9: Renal osteodystrophy. Loss of a sharp trabecular pattern that results in a ground glass density of the bone on sagittal radiograph of the skull (a) and corresponding sagittal (b) and axial (c and d) CT images. Multicentric sclerotic lesions may represent focal areas of osteosclerosis related to secondary hyperparathyroidism.

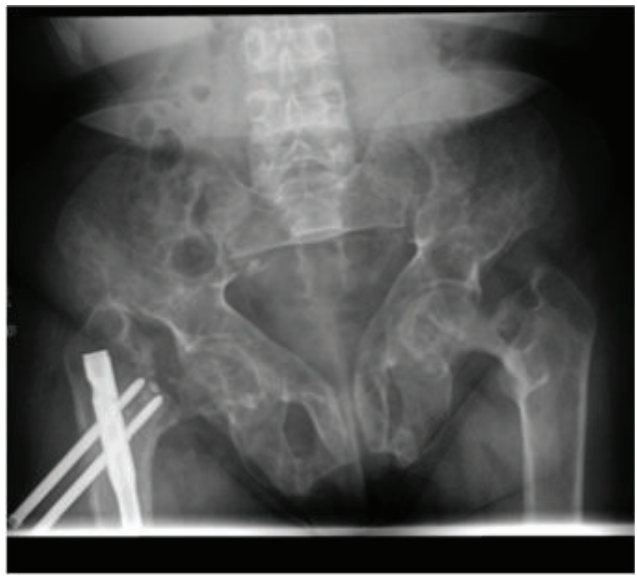

(a)

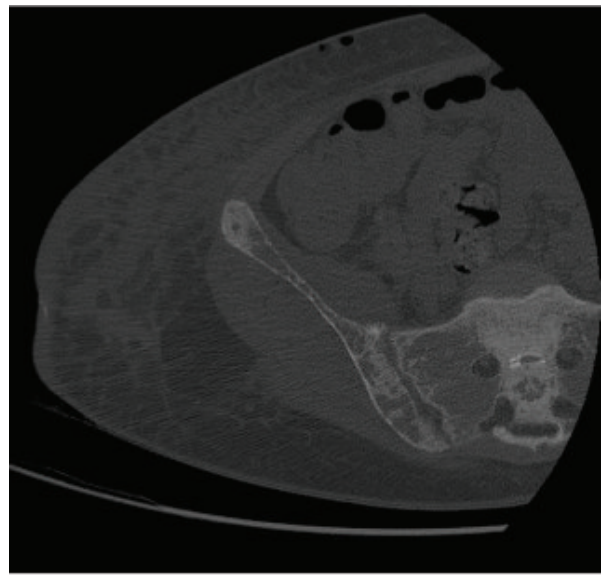

(b)

FIGURE 10: Renal osteodystrophy. AP view of the pelvis (a) in a 26-year-old female with secondary hyperparathyroidism that results in multiple, circumscribed, and expanded lucent areas compatible with brown tumors. Associated fracture deformity of the right femoral head and generalized demineralization. Prominent subchondral resorption and subtle widening, notably along the iliac surface of the right sacroiliac joint on axial CT image (b). 


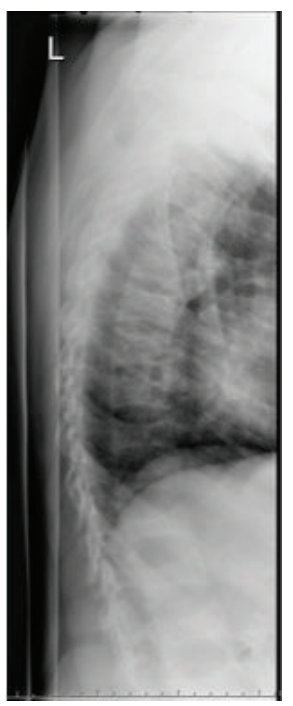

(a)

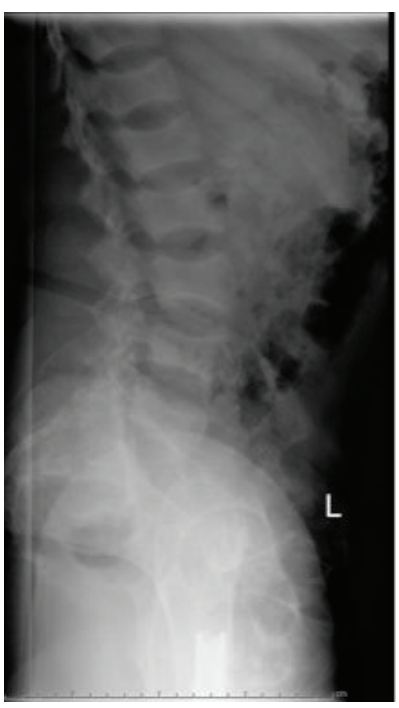

(b)

FIGURE 11: Renal osteodystrophy. Biconcave deformities of multiple vertebral bodies and subtle bands of sclerosis adjacent to the endplates on lateral radiographs of the thoracic (a) and lumbar spine (b) in a 30-year-old female.

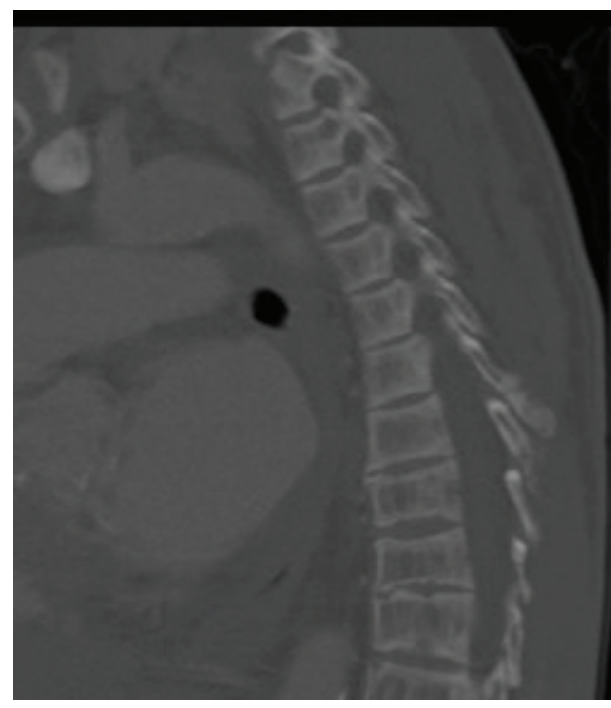

(a)

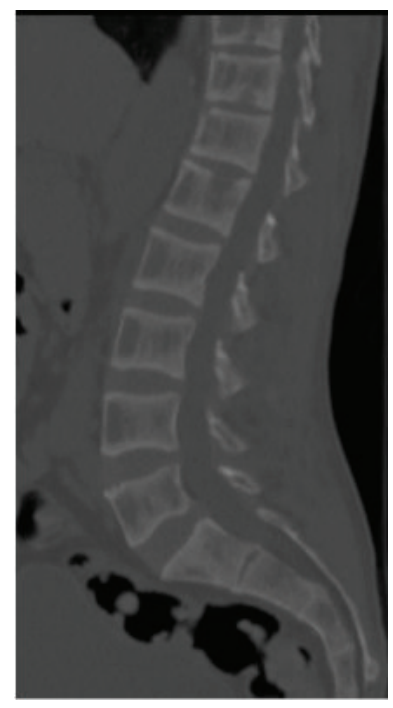

(b)

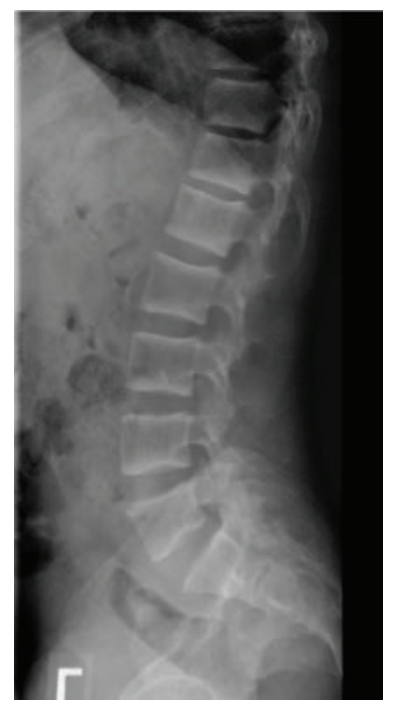

(c)

FIGURE 12: Renal osteodystrophy. Prominent trabecular pattern secondary to generalized trabecular resorption in a 32-year-old male with end-stage renal disease on sagittal CT images ( $\mathrm{a}$ and $\mathrm{b}$ ) and corresponding lateral lumbar spine radiograph (c). Sclerotic bands adjacent to the vertebral endplates result in subtle "rugger jersey spine" secondary to the excess osteoid.

the disease may affect any bone [58]. Of the vertebrae, the body is almost always involved with occasionally some posterior elements. The lumbar spine is the most frequently affected, followed by the thoracic and then cervical spine [59]. Paget's disease in long bones does not spread to adjacent bones but instead tends to envelope the original bone entirely if allowed to progress [60].

7.2. Radiographic Features. Paget's disease, largely asymptomatic, is often an incidental finding on radiography [59]. Radiography can help distinguish osteoblastic versus osteolytic lesions as well as demonstrate characteristic findings such as cortical thickening and tunneling, trabecular thickening, generalized bone enlargement, and deformities. Of note, Paget's lesions do not cross normal articular surfaces and rarely involve new bone over long periods of time. Although small fissures may form in pagetic bone that appear similar to the pseudofractures of osteomalacia, the fissures in Paget's disease occur on the convex portion of the bone versus the concave side in osteomalacia [13].

There are three phases of Paget's disease with unique radiological features, although they can occur in synchrony [61]. 


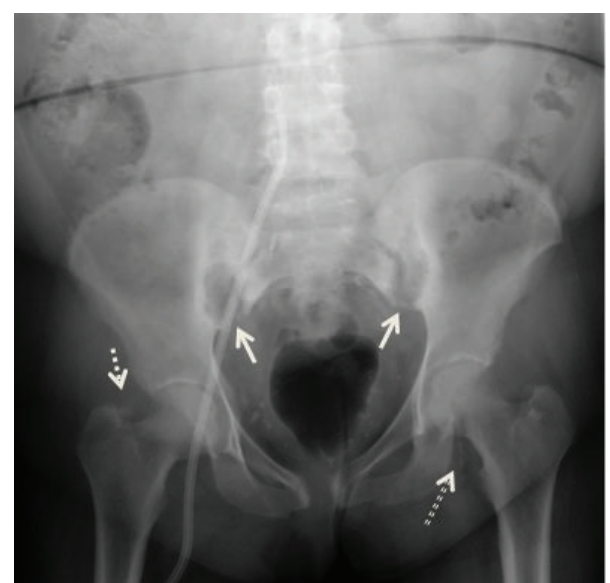

FIGURE 13: Renal osteodystrophy. A 57-year-old female with endstage renal disease which results in prominent subchondral resorption resulting in widening of bilateral sacroiliac joints along the iliac surface on AP view of the pelvis (solid arrows). Soft tissue calcifications adjacent to right greater trochanter (dashed arrows), vascular calcification adjacent to the left femoral head (double dashed arrows), and a right femoral dialysis catheter.

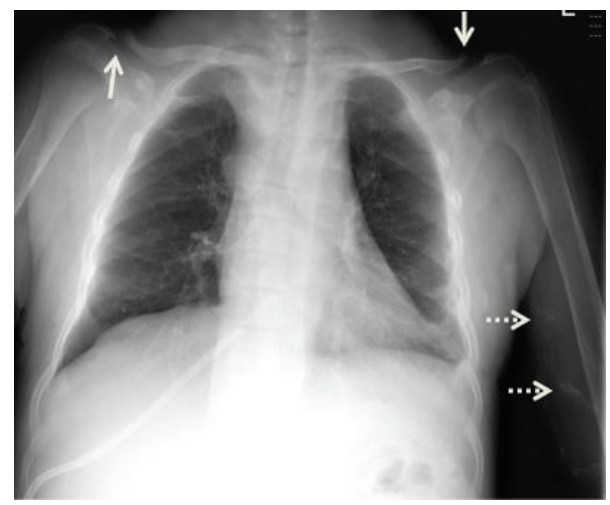

FIGURE 14: Renal osteodystrophy. A 40-year-old male with endstage renal disease resulting in prominent subchondral resorption at the distal clavicles on PA chest radiograph (solid arrows). Soft tissue calcifications adjacent to the left humerus (dashed arrows) and transhepatic dialysis catheter.

The first phase is lytic with an advancing edge of resorption to produce a geographic appearance. This phenomenon in long bones begins in the subchondral epiphysis or metaphysis and extends toward the diaphysis. The advancing front results in a "cutting-cone," "blade of grass," or "candle flame" sign [62]. In the calvarium, this process is termed "osteoporosis circumscripta" and tends to affect the frontal and occipital bones with a well-demarcated, oval conformation. It can also cross suture lines. Rarely, the lesions may arise in the diaphysis without epiphyseal involvement, but this pattern is unique to the tibia [63].

The second or mixed lytic-sclerotic stage is usually when Paget's disease is most commonly diagnosed. In addition to cortical thickening, trabecular coarsening, and osseous expansion, endosteal growth can encroach the medullary cavity to produce loss of corticomedullary differentiation (Figure 15). These mixed lesions produce a "cotton-wool" pattern in the skull and a "picture-frame" pattern in the vertebral column [61].

The final or sclerotic phase of Paget's disease is the result of rapid new bone formation causing widespread increase in density, medullary sclerosis, and overall bone size. It should be noted that lesions seen on plain radiographs but not scintigraphy are most likely older or "burned out" lesions [61].

Although many other metabolic bone diseases affect the spine, Paget's disease can form characteristic vertebrae with coarse, dense trabecular structure, and a more dense periphery on lateral spine radiographs. This is termed the "window pane" appearance in the setting of Paget's disease. These vertebrae have a reduced height but are increased in diameter due to compromised structural integrity; this fact can be extremely helpful in differentiating pagetoid bone from other bone pathology [2]. Sarcomatous degeneration is a significant complication of Paget's disease that most commonly arises in the pelvis or femur and is rarely multifocal [64]. Sarcomas generally appear osteolytic on radiography and are accompanied by other radiological signs of malignancy. MRI can be useful to discern sarcomatous degeneration by helping to visualize cortical disruption or effacement of normal structures [65].

7.3. Computed Tomography (CT). Aside from lesions in complex anatomical areas such as the facial bones, neural foramina, and middle ear, CT provides only limited additional information to warrant usage over plain radiography for uncomplicated Paget's disease. However, CT along with MRI can be utilized to evaluate possible fractures or sarcomatous degeneration. Lytic lesions are enhanced with IV contrast in both modalities [63].

7.4. Magnetic Resonance (MR) Imaging. The disease has a number of characteristic findings on MR imaging. The cortex appears thickened and striated on $\mathrm{T} 1$ sequences. Osteolytic foci have low signal intensity on $\mathrm{T} 1$ sequences but high intensity on T2. Additionally, the fatty bone marrow signal is preserved in T1-weighted sequences of uncomplicated Paget's disease, which is significant because this signal is diminished with complications such as acute fracture or sarcoma [66]. MRI is also useful in assessing nerve compression from expanding bone [67].

7.5. Nuclear Imaging. Bone scintigraphy is one of the principal modalities for assessing the extent of Paget's disease since it allows an overview of the entire skeleton. In the detection of Paget's lesions, bone scintigraphy is more sensitive than plain radiography due to the increased perfusion in these foci [61]. Paget's lesions represent metabolically active areas with high bone turnover that are readily visible due to increased tracer uptake (Figure 16) [13]. Osteoporosis circumscripta may show peripherally increased but centrally decreased tracer uptake. Uptake in long bones may abut one joint and extend into the diaphysis [61]. 


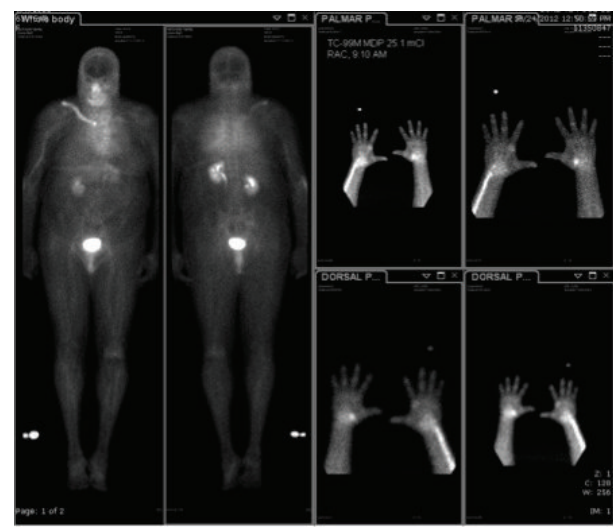

(a)

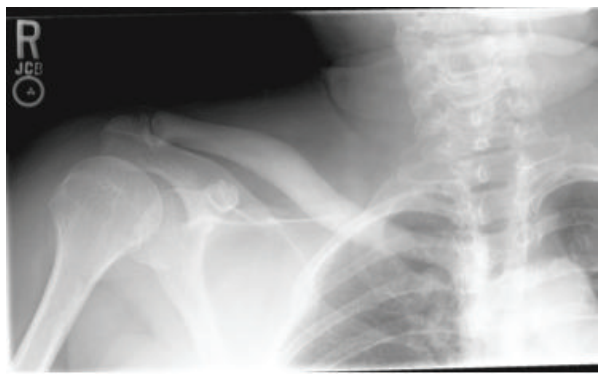

(c)

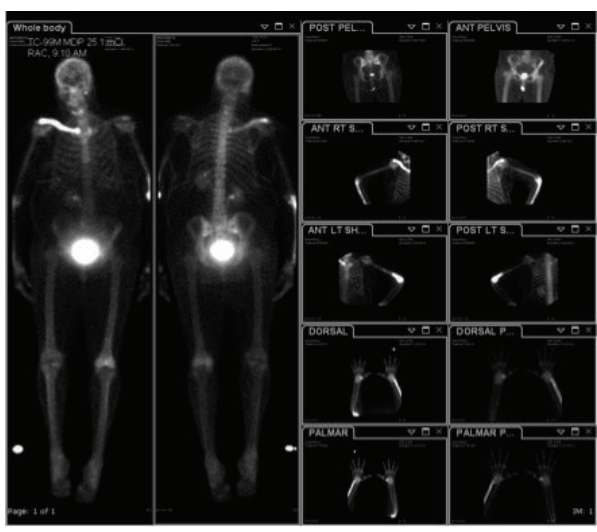

(b)

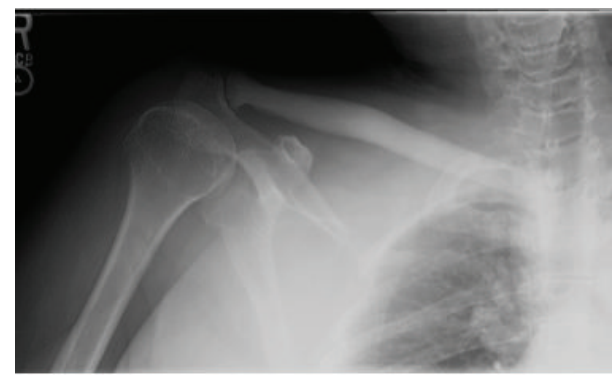

(d)

FIGURE 15: Paget's disease. Three phase bone scan ( $\mathrm{a}$ and $\mathrm{b}$ ) in a 61-year-old female with increase uptake on delayed phase images in the right clavicle, left distal humerus, right ulna, and the left femoral condyles consistent with polyostotic involvement of Paget's disease. Markedly sclerotic appearance with loss of corticomedullary on corresponding radiographs of the right clavicle (c and d).

On the other hand, lesions with low activity are difficult to detect with radioactive tracers and must require radiography for adequate visualization [66]. Bone scans may also provide a window for earlier detection and treatment in that it can reveal lesions even with normal alkaline phosphatase activity [68].

Only one-third of patients with Paget's disease exhibit increased FDG uptake, which is why the role of PET is still undetermined. However, because lesions that do appear on PET may cause confusion in patients with concurrent skeletal metastases, it is important to utilize CT to evaluate existing lesions in these patients [69].

\section{Osteogenesis Imperfecta}

8.1. General Radiographic Manifestations. Osteogenesis imperfecta, or "brittle bone disease," is an inherited disorder caused by the deficiency or defect of collagen type I resulting in increased bone fragility and decreased bone mass [70]. There are several forms of the disorder that can range widely in morbidity and mortality. The milder forms, such as type I, may cause only minimal bone deformities aside from scoliosis resulting from vertebral fractures [70].

In general, OI is often classified as a metabolic bone disease as radiography reveals patterns of both bone destruction and deposition, although similar patterns are seen in other disorders of the bone that result in fractures in various states of healing (Figure 17). Cortical thinning results from abnormal bone structure, lack of lamellar bone, replacement of compact bone by spongiform bone, and defective endochondral and periosteal bone formation [71]. Cortical thinning can also misleadingly cause bones to appear wider in diameter on radiographs than in actuality. Additionally, long bones may be significantly bowed. Like with osteoporosis, trabeculae appear thin, delicate, and widely spaced [72]. Most OI patients develop secondary osteoporosis, and postmenopausal women can be particularly vulnerable [73].

In addition, diffuse osteopenia, sclerosis of the vertebral endplates, and biconcave vertebral bodies may result [71]. Vertebral disease often causes severe kyphoscoliosis and platyspondyly or decreased height in the thoracic vertebrae [74]. Similar to other metabolic bone diseases, OI can produce "fish mouth" vertebrae on lateral radiographs due to deformity in vertebral endplates, which causes intervertebral disc spaces to appear as biconvex or ellipsoid areas. Patients with type II OI can develop generalized osteoporosis with minimal vertebral ossification [71]. A small proportion of patients (5\%) can also suffer from spondylolisthesis [75]. Milder forms of OI may exhibit only subtle radiographic changes [73].

In some forms of osteogenesis imperfecta, radiographic examination may reveal a dense band adjacent to the growth plate of long bones [73]. Additionally, the interosseous membrane of the forearm may undergo marked calcification, 


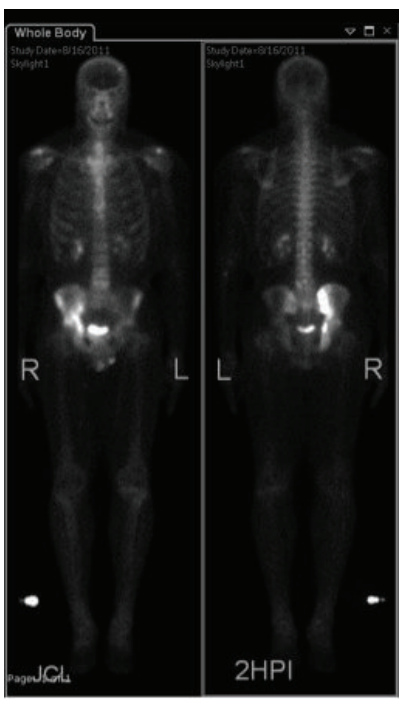

(a)

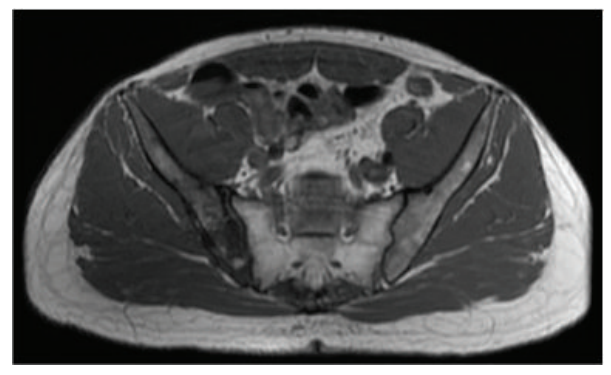

(b)

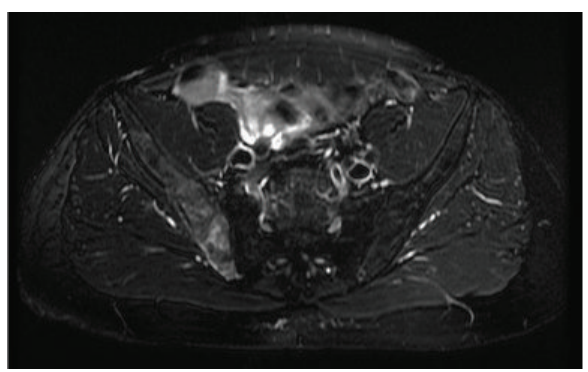

(c)

Figure 16: Paget's disease. Osteoblastic activity in the right iliac bone on nuclear medicine bone scan in a 60-year-old male with Paget's disease. On axial T1 and T2 fat saturated MRI sequences (b and c) through the pelvis, heterogeneous T1 and T2 marrow signal intensity (but with preservation of fatty marrow signal), cortical thickening, and expansile remodeling of the right iliac bone.

which can restrict forearm rotation in these patients [76]. Abnormal calcification within the middle ear as well as persistent cartilage often causes hearing difficulty and can appear similar to otosclerosis on CT scans [73].

Around one-third to one-half of OI patients may develop dentinogenesis imperfecta, which the teeth appear misshapen and brown or opalescent on exam. Radiographically, the teeth may have bulbous crowns, narrow roots, and narrow or obliterated pulp chambers [73].

8.2. Types of Osteogenesis Imperfecta. There are multiple types of osteogenesis imperfecta. In general, type I is the most common type and is mild without associated deformity, while type II is the least common type and is fatal in the perinatal period. Type III is severely deforming while type IV is deforming but less so than type III [71]. In type I or mild OI, fractures are less common after puberty due to completion of ossification and adult patients may indeed have normal bone density [71]. Type I represents around half of all OI cases and is different from the other phenotypes of the disease in that long bone fractures in these patients tend to heal without major deformity. Although osteopenia is present, long bones in OI type I generally do not bow. However, platyspondyly and scoliosis of approximately 20 degrees can be expected in the vertebral column. Type I patients may have a characteristic triangular face shape resulting from frontal bossing accompanied by a narrowed mandible. DEXA scans can reveal decreased bone mineral density in even mild cases of the disease [73].

On the other hand, type II or lethal OI is characterized by in utero fractures of the skull, vertebrae, and long bones, as well as by decreased vertebral ossification, beaded ribs, and a small chest cage. These patients usually die within one year of birth due to pulmonary hypoplasia or cerebral hemorrhage [71]. Although birth weight and length are small for gestational age, the skull tends to be disproportionately large. Limbs can be shortened and bowed, with legs often abducted perpendicular to the body in a "frog leg" position [73]. Additionally, the thorax can take on a characteristic conical or "beehive" shape in these patients [77]. Type III OI is similar to type II OI in that it is evident at birth, although more severe. Like with type II OI, significant deformity throughout the skeleton may occur. However, unlike type II patients, type III patients lack the beaded appearance of ribs and crumpling of long bones. Type III patients also share the triangular facies seen in type I patients. However, 


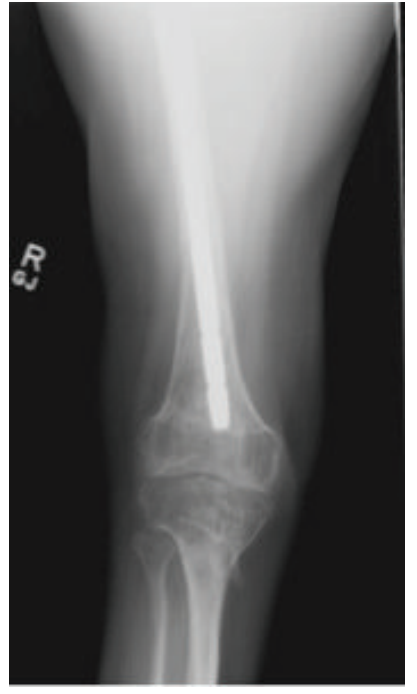

(a)

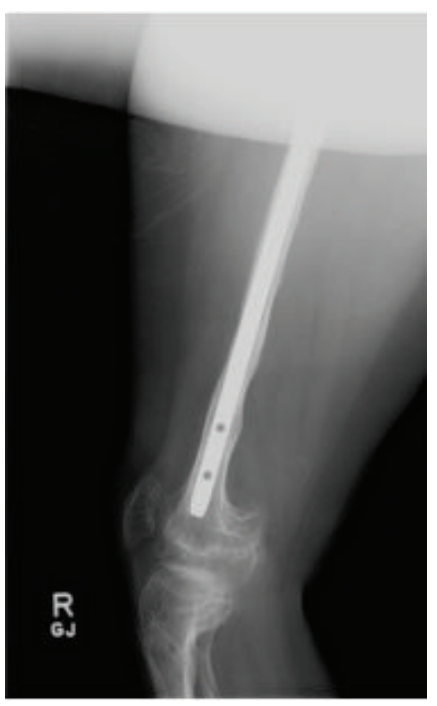

(b)

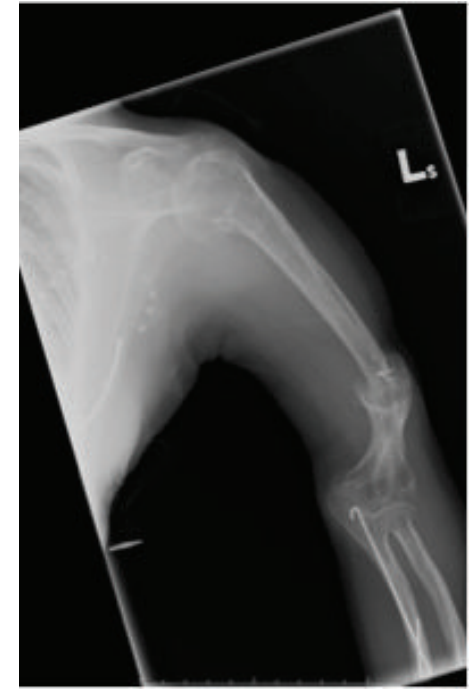

(c)

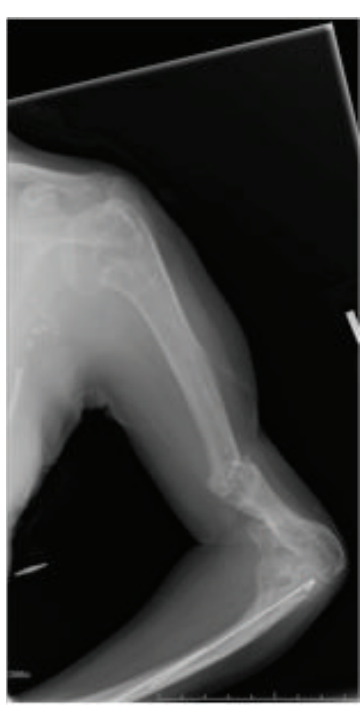

(d)

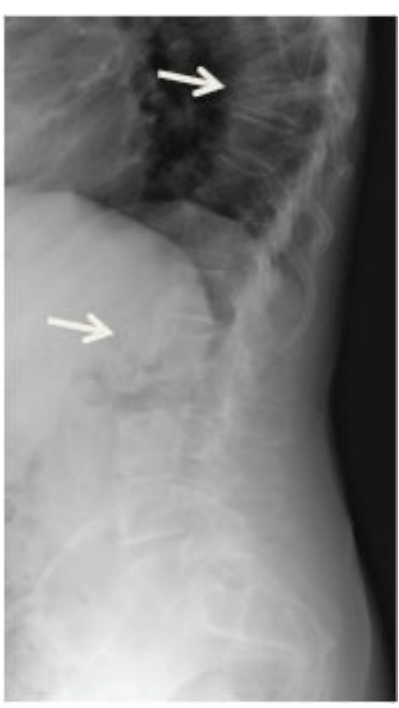

(e)

FIGURE 17: Osteogenesis imperfecta. AP and lateral radiographs of the right femur ( $a$ and b) and left humerus (c and d) in a 54-year-old female with osteogenesis imperfecta with multiple fractures in various stages of healing and prominent generalized demineralization. Compression deformities at T8 and L1 on lateral radiograph of the lumbar spine (solid arrows) (e)

an additional deformity called the "helmet deformity" may arise as a result of cranial molding causing an occipital protrusion [73].

It should be noted that up to $5 \%$ patients with OI type $\mathrm{V}$ can develop a hyperplastic callus that can mimic osteosarcoma unless further distinguished by MRI or CT $[78,79]$.

8.3. DEXA and OI. Although it can be difficult to clinically differentiate mild osteogenesis imperfecta from child abuse, dual energy X-ray absorptiometry can be used to aid diagnosis in conjunction with radiography. DEXA of the anteroposterior spine has a sensitivity of $91.7 \%$ and DEXA of the whole body has a specificity of $100 \%$ in detecting osteogenesis imperfecta [80]. Children with OI may receive annual DEXA scans to assess development and predict fractures, but there is little data on predicted values of bone mineral density in infants with the disease [70]. DEXA is also useful in tracking the effectiveness of therapy such as bisphosphonates [73]. Compared to plain radiography, DEXA has a much lower radiation dose at around $10 \%$ of that required for a chest radiography [81]. DEXA and other techniques used to monitor BMD in osteoporosis can be applied to OI patients. It should be noted that the short stature of many OI patients can result in artificially low BMD readings, making them especially difficult to interpret [81].

8.4. Cranial Findings. OI patients may present with a triangular face shape and frontal bossing, which may be accompanied by mandibular malformation, especially prognathism. Accessory or "Wormian" bones along the sutures is caused 


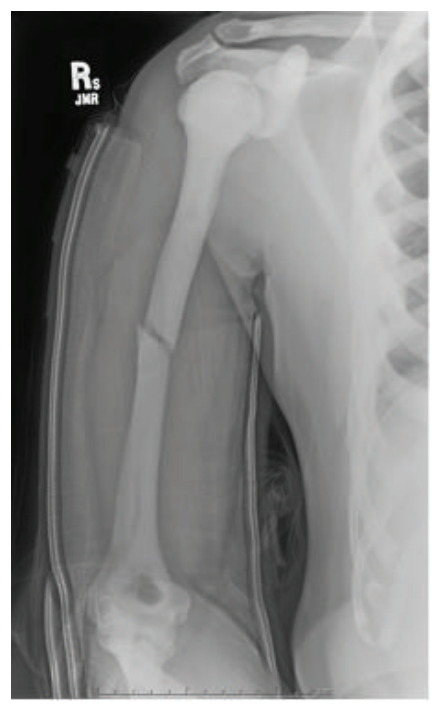

(a)

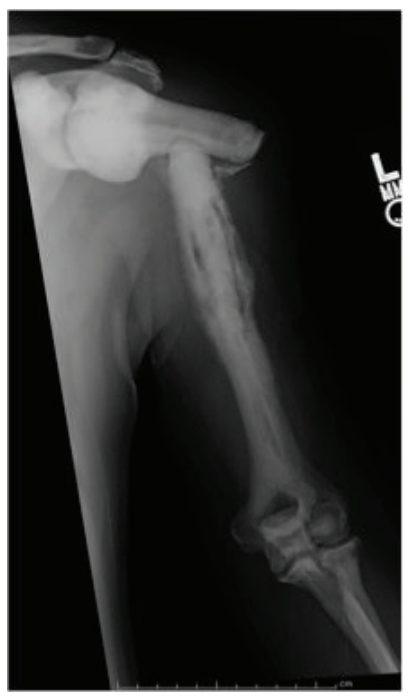

(c)

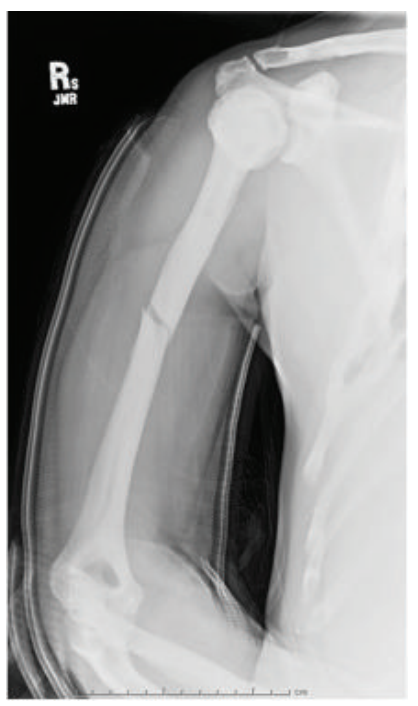

(b)

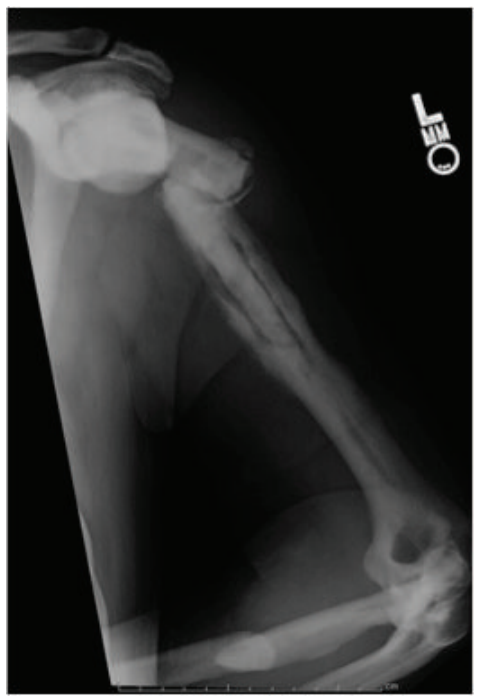

(d)

FIGURE 18: Osteopetrosis. Acute fracture of the right humeral diaphysis in a 46-year-old male with osteopetrosis on right humeral radiographs ( $a$ and $b$ ). Left humeral radiographs ( $c$ and $d$ ) in the same patient with chronic pathologic fracture deformity of the left humerus. The bones are diffusely dense with loss of normal corticomedullary differentiation.

by impaired membranous and endochondral bone formation. Sutures may also be prematurely closed and may result in brachycephaly (widened frontal fontanel) if the coronal suture fuses prematurely with associated overgrowth of the sagittal and lambdoid sutures [71].

8.5. Neurological Findings. An interesting manifestation of OI is the development of moyamoya disease, which can result in subarachnoid hemorrhage. Additional vascular disease associated with OI includes carotid cavernous fistulas as well as cervical artery dissection and cerebral vessel aneurysms $[82,83]$. In utero vascular compression due to poor positioning may result in unilateral cerebellar hypoplasia [84]. OI patients can also have diffusely atrophied cerebral hemispheres and/or hydrocephalus $[85,86]$. In fetuses with a familial history of OI, prenatal ultrasound screening has been recommended in the second trimester to detect manifestations such as ventriculomegaly, rhizomelia, and femoral deformity [87]. Intrauterine fractures for the most severe forms of OI can be detected as early as 14 weeks' gestation while some are not apparent until 20 weeks. However, type I OI fractures can be mild enough to escape detection in utero [73].

8.6. Craniocervical Junction Findings. The softening of the bones in OI patients can result in a number of abnormalities in the craniocervical junction. One manifestation is basilar invagination, which refers to the upward protrusion of the odontoid process into the foramen magnum [87]. Although conventional lateral skull radiography can detect 


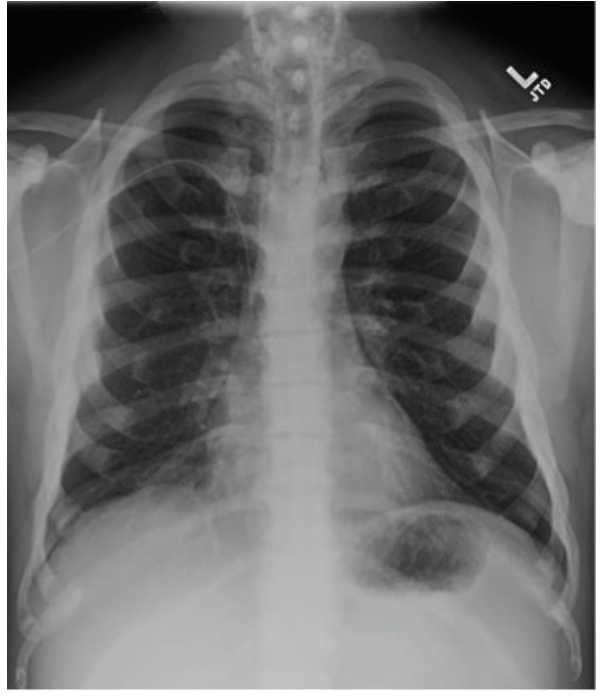

(a)

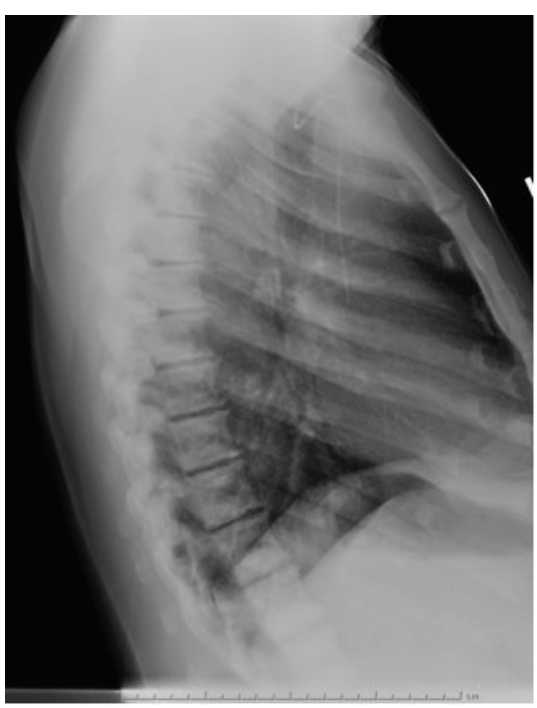

(b)

FiguRE 19: Osteopetrosis. PA (a) and lateral (b) radiographs of the chest in a 46-year-old male with osteopetrosis. Multiple right rib fractures, diffusely sclerotic bones, and sharply demarcated sclerotic bands are seen adjacent to the end plates, forming "sandwiched vertebral bodies."

basilar invagination, MRI is the best modality for depicting craniospinal manifestations of this disease, especially in the evaluation of tonsillar herniation and posterior fossa abnormalities [88].

Another deformity, called platybasia or basilar impression, results from the upward infolding of the foramen magnum into the skull, which can cause displacement of the brainstem [71]. It can affect up to $25 \%$ of OI patients [73]. Either basilar invagination or basilar impression can result in aqueductal stenosis, hydrocephalus, cord edema, or syrinx [86].

\section{Acromegaly}

9.1. General. Acromegaly is characterized by excessive growth hormone secretion from a pituitary adenoma and, occasionally, hyperplasia of eosinophilic cells. Growth hormone $(\mathrm{GH})$ produces several systemic manifestations and progressive somatic disfigurement. Main clinical features are prominent forehead, mandibular hyperplasia, thickened tongue and broadening of extremities, and soft tissue thickening. Gigantism results if GH production occurs prior to closure of long bone growth centers. Bitemporal hemianopsia and chronic headaches are effects of progressive growth of adenoma.

Skeletal effect of growth hormone is to stimulate chondrocytes, fibroblasts, and osteocytes which results in new bone formation and consequent irregular thickening of the cortex [35, 47]. Musculotendinous insertions develop bony excrescences and bony spurs which indicate an overall increase in ectopic bone formation. Carpal tunnel syndrome may be a combination of soft tissue hypertrophy and bony overgrowth with edema within the nerve itself $[35,47]$.
9.2. Radiographic Features. Soft tissue changes are most notable in the hands and feet and heel pad thickness of $>20 \mathrm{~mm}$ is suggestive, although not pathognomonic of acromegaly [89]. Bony changes include widening of phalangeal shafts and metacarpals, prominent ungual tufts, and bony protuberances [35]. Initially, there is generalized increase in joint space due to cartilage overgrowth, but there is fissuring and ulceration of the cartilage over time and results in degenerative joint disease with bony remodeling, osteophytes, and enthesopathic changes. Joints affected at an early stage include knees, shoulders, elbows, and hips [47].

Skull changes include enlargement and erosion of the sella, widened mandibular angle, hyperplasia of sinuses, occipital protuberance overgrowth, and malocclusion [35, 90]. In the spine, sagittal and transverse dimensions of vertebral bodies increase, whereas vertebral body heights remain unchanged, resulting in platyspondyly [35]. Widened disc heights, widened atlantodental interspace, posterior body scalloping, premature degeneration, and exuberant osteophytes are other classic findings. Thickening of lamina, spinal ligaments, and articular processes may rarely result in spinal stenosis [35].

\section{Osteopetrosis}

10.1. General. Osteopetrosis, also known as marble bone disease or Albers-Schönberg disease, is a rare hereditary disorder that should be considered in the differential for sclerotic bones. Because it is characterized by defective osteoclastic activity, the disorder is often classified as a metabolic bone disease [91]. Genetic mutations have been identified to be responsible and while several heterogeneous forms of osteopetrosis have been recognized, there are two main forms: infantile autosomal recessive form that is severe, and 
the benign adult autosomal dominant osteopetrosis [92-94]. Underlying pathogenesis for both entities involves defective osteoclast function that disrupts the normal equilibrium between bone formation and resorption. Continued production of bone results in remodeling of the primary spongiosa and leads to dense, sclerotic bones with weak structural integrity. Defect in remodeling bone at the endosteum results in failure to create normal marrow spaces that clinically manifests as anemia with extramedullary hematopoiesis, or in severe cases, leukemia [94, 95]. Despite the increased density of the bones, decrease in osteoclastic activity leads to lack of structural integrity that predisposes to fractures at sites of stress and heals with abundant callus formation $[92,94]$.

10.2. Radiologic Features. Radiologic manifestations in the infantile form are severe dental caries, fractures from minor trauma, cranial vault and skull base thickening, diffuse involvement of the axial and appendicular skeleton, and splayed metaphyses that are commonly seen as transverse lucencies $[93,94]$. There is loss of corticomedullary differentiation and bones are uniformly dense with smooth margins (Figure 18). Crowding and underdevelopment of marrow spaces are most prominent in the distal femur [94].

In the benign adult types, two different phenotypes exist [96]. In Type 1 phenotype, there is cranial vault osteosclerosis without involvement of the skull base and limited involvement of the appendicular skeleton and spine [96]. In Type 2, diffuse osteosclerosis with involvement of the skull base is noted. Due to lack of remodeling, continued deposition of bony matrix results in "bone within bone" appearance that is most evident in the spine and ilium [96]. Dense sclerotic appearance of the endplates causes "sandwich" appearance of vertebrae that can be confused with "rugger jersey" spine appearance [96] (Figure 19). Although the two entities are difficult to differentiate, osteopetrosis generally causes a more defined and dense appearance of the endplates. Treatment is focused on symptomatic relief, with stem cell transplantation reserved for the more severe forms [93].

\section{Conclusion}

Metabolic bone disease is a diverse spectrum of pathology affecting bone homeostasis. Imaging is essential for the diagnosis, evaluation, and treatment of these patients. Knowledge of the diseases, recognition of the imaging findings, and expertise to appropriately guide the imaging evaluation and treatment are fundamental to the role of the radiologist.

\section{Conflict of Interests}

The authors declare that they have no conflict of interests regarding the publication of this paper.

\section{References}

[1] J. E. Adams, "Advances in bone imaging for osteoporosis," Nature Reviews Endocrinology, vol. 9, no. 1, pp. 28-42, 2013.
[2] G. Guglielmi, S. Muscarella, and A. Bazzocchi, "Integrated imaging approach to osteoporosis: state-of-the-art review and update," Radiographics, vol. 31, no. 5, pp. 1343-1364, 2011.

[3] W. H. Harris and R. P. Heaney, "Skeletal renewal and metabolic bone disease," The New England Journal of Medicine, vol. 280, no. 6, pp. 303-311, 1969.

[4] M. Singh, A. R. Nagrath, and P. S. Maini, "Changes in trabecular pattern of the upper end of the femur as an index of osteoporosis," Journal of Bone and Joint Surgery. American Volume, vol. 52, no. 3, pp. 457-467, 1970.

[5] B. L. Riggs and L. J. Melton III, "Evidence for two distinct syndromes of involutional osteoporosis," The American Journal of Medicine, vol. 75, no. 6, pp. 899-901, 1983.

[6] S. Grampp, H. K. Genant, A. Mathur et al., "Comparisons of noninvasive bone mineral measurements in assessing agerelated loss, fracture discrimination, and diagnostic classification," Journal of Bone and Mineral Research, vol. 12, no. 5, pp. 697-711, 1997.

[7] L. J. Melton III, E. J. Atkinson, C. Cooper, W. M. O'Fallon, and B. L. Riggs, "Vertebral fractures predict subsequent fractures," Osteoporosis International, vol. 10, no. 3, pp. 214-221, 1999.

[8] T. M. Link, G. Guglielmi, C. van Kuijk, and J. E. Adams, "Radiologic assessment of osteoporotic vertebral fractures: diagnostic and prognostic implications," European Radiology, vol. 15, no. 8, pp. 1521-1532, 2005.

[9] H. K. Genant, C. Y. Wu, C. Van Kuijk, and M. C. Nevitt, "Vertebral fracture assessment using a semiquantitative technique," Journal of Bone and Mineral Research, vol. 8, no. 9, pp. 1137-1148, 1993.

[10] G. Guglielmi, S. Muscarella, A. Leone, and W. C. G. Peh, "Imaging of metabolic bone diseases," Radiologic Clinics of North America, vol. 46, no. 4, pp. 735-754, 2008.

[11] A. Rosholm, L. Hyldstrup, L. Backsgaard, M. Grunkin, and H. H. Thodberg, "Estimation of bone mineral density by digital $\mathrm{X}$-ray radiogrammetry: theoretical background and clinical testing," Osteoporosis International, vol. 12, no. 11, pp. 961-969, 2001.

[12] M. Singh, B. L. Riggs, J. W. Beabout, and J. Jowsey, "Femoral trabecular-pattern index for evaluation of spinal osteoporosis," Annals of Internal Medicine, vol. 77, no. 1, pp. 63-67, 1972.

[13] G. Haugeberg, "Imaging of metabolic bone diseases," Best Practice and Research: Clinical Rheumatology, vol. 22, no. 6, pp. 1127-1139, 2008.

[14] J. Compston, "Management of glucocorticoid-induced osteoporosis," Nature Reviews Rheumatology, vol. 6, no. 2, pp. 82-88, 2010.

[15] D. M. Reid, J. Doughty, R. Eastell et al., "Guidance for the management of breast cancer treatment-induced bone loss: a consensus position statement from a UK Expert Group," Cancer Treatment Reviews, vol. 34, no. 1, pp. S3-S18, 2008.

[16] J. E. Adams and N. Bishop, Dual Energy X-Ray Absorptiometry (DXA) in Adults and Children, American Society for Bone and Mineral Research, Washington, DC, USA, 7th edition, 2009.

[17] C. C. Gluer, "Monitoring osteoporosis treatment," Journal of Bone and Mineral Research, vol. 14, pp. 1952-1962, 1999.

[18] N. B. Watts, "Fundamentals and pitfalls of bone densitometry using dual-energy X-ray absorptiometry (DXA)," Osteoporosis International, vol. 15, no. 11, pp. 847-854, 2004.

[19] A. El Maghraoui and C. Roux, "DXA scanning in clinical practice," QJM: An International Journal of Medicine, vol. 101, no. 8, pp. 605-617, 2008. 
[20] L. G. Dasher, C. D. Newton, and L. Lenchik, "Dual X-ray absorptiometry in today's clinical practice," Radiologic Clinics of North America, vol. 48, no. 3, pp. 541-560, 2010.

[21] E. M. B. Pacheco, E. J. Harrison, K. A. Ward, M. Lunt, and J. E. Adams, "Detection of osteoporosis by dual energy X-ray absorptiometry (DXA) of the calcaneus: is the WHO criterion applicable?" Calcified Tissue International, vol. 70, no. 6, pp. 475-482, 2002.

[22] World Health Organization, "FRAX WHO fracture risk assessment tool," 2013, http://www.shef.ac.uk/FRAX/.

[23] J. Damilakis, J. E. Adams, G. Guglielmi, and T. M. Link, "Radiation exposure in X-ray-based imaging techniques used in osteoporosis," European Radiology, vol. 20, no. 11, pp. 27072714, 2010.

[24] J. T. Schousboe, B. C. Taylor, D. P. Kiel, K. E. Ensrud, K. E. Wilson, and E. V. McCloskey, "Abdominal aortic calcification detected on lateral spine images from a bone densitometer predicts incident myocardial infarction or stroke in older women," Journal of Bone and Mineral Research, vol. 23, no. 3, pp. 409-416, 2008.

[25] D. Hans, N. Barthe, S. Boutroy, L. Pothuaud, R. Winzenrieth, and M.-A. Krieg, "Correlations between trabecular bone score, measured using anteroposterior dual-energy X-ray absorptiometry acquisition, and 3-dimensional parameters of bone microarchitecture: an experimental study on human cadaver vertebrae," Journal of Clinical Densitometry, vol. 14, no. 3, pp. 302-312, 2011.

[26] G. Guglielmi and T. F. Lang, "Quantitative computed tomography," Seminars in Musculoskeletal Radiology, vol. 6, no. 3, pp. 219-227, 2002.

[27] G. Guglielmi and S. Muscarella, "Axial CT in the diagnosis of osteoporosis," Clinical Cases in Mineral and Bone Metabolism, vol. 2, no. 2, pp. 110-112, 2005.

[28] W. Yu, C. Glüer, S. Grampp et al., "Spinal bone mineral assessment in postmenopausal women: a comparison between dual X-ray absorptiometry and quantitative computed tomography," Osteoporosis International, vol. 5, no. 6, pp. 433-439, 1995.

[29] T. F. Lang, "Quantitative computed tomography," Radiologic Clinics of North America, vol. 48, no. 3, pp. 589-600, 2010.

[30] S. Prevrhal, K. Engelke, and W. A. Kalender, "Accuracy limits for the determination of cortical width and density: the influence of object size and CT imaging parameters," Physics in Medicine and Biology, vol. 44, no. 3, pp. 751-764, 1999.

[31] M. A. Moyad, "Osteoporosis: a rapid review of risk factors and screening methods," Urologic Oncology, vol. 21, no. 5, pp. 375379, 2003.

[32] C. Chappard, G. Berger, C. Roux, and P. Laugier, "Ultrasound measurement on the calcaneus: Influence of immersion time and rotation of the foot," Osteoporosis International, vol. 9, no. 4, pp. 318-326, 1999.

[33] M.-A. Krieg, R. Barkmann, S. Gonnelli et al., "Quantitative ultrasound in the management of osteoporosis: the 2007 ISCD official positions," Journal of Clinical Densitometry, vol. 11, no. 1, pp. 163-187, 2008.

[34] A. J. Burghardt, T. M. Link, and S. Majumdar, "High-resolution computed tomography for clinical imaging of bone microarchitecture," Clinical Orthopaedics and Related Research, vol. 469, no. 8, pp. 2179-2193, 2011.

[35] T. R. Yochum and L. J. Rowe, Essentials of Skeletal Radiology, Lippincott Williams \& Wilkins, Baltimore, Md, USA, 3rd edition, 2004.
[36] M. D. Murphey, D. J. Sartoris, J. L. Quale, M. N. Pathria, and N. L. Martin, "Musculoskeletal manifestations of chronic renal insufficiency.", Radiographics, vol. 13, no. 2, pp. 357-379, 1993.

[37] W. Heird, "Vitamin deficiencies and excesses," in Nelson Textbook of Pediatrics, R. E. Behrman, R. M. Kiegman, A. M. Arvin, and W. E. Nelson, Eds., WB. Saunders, Philadelphia, Pa, USA, 17th edition, 2003.

[38] O. Fain, "Musculoskeletal manifestations of scurvy," Joint Bone Spine, vol. 72, no. 2, pp. 124-128, 2005.

[39] W. Dähnert, Dahnert Radiology Review Manual, Lippincott Williams \& Wilkins, Philadelphia, Pa, USA, 2007.

[40] A. Bonakdarpour, W. Reinus, and J. Khurana, Diagnostic Imaging of Musculoskeletal Diseases: A Systematic Approach, Springer, New York, NY, USA, 2009.

[41] D. Resnick and G. Niwayama, "Parathyroid disorders and renal osteodystrophy," in Diagnosis of Bone and Joint Disorders, D. Resnick and G. Niwayama, Eds., WB Saunders, Philadelphia, $\mathrm{Pa}, \mathrm{USA}, 1995$.

[42] A. Wittenberg, "The rugger jersey spine sign," Radiology, vol. 230, no. 2, pp. 491-492, 2004.

[43] S. Karani, "Secondary hyperparathyroidism: primary renal failure," Proceedings of the Royal Society of Medicine, vol. 48, pp. 527-530, 1955.

[44] M. J. Pitt, "Rickets and osteomalacia," in Diagnosis of Bone and Joint Disorders, D. Resnick, Ed., Saunders, Philadelphia, Pa, USA, 3rd edition, 1995.

[45] M. Ketteler, H. Rothe, T. Krüger, P. H. Biggar, and G. Schlieper, "Mechanisms and treatment of extraosseous calcification in chronic kidney disease," Nature Reviews Nephrology, vol. 7, no. 9, pp. 509-516, 2011.

[46] W. J. Johnson, R. S. Goldsmith, J. W. Beabout, J. Jowsey, P. J. Kelly, and C. D. Arnaud, "Prevention and reversal of progressive secondary hyperparathyroidism in patients maintained by hemodialysis," The American Journal of Medicine, vol. 56, no. 6, pp. 827-832, 1974.

[47] G. Dumoulin, B. Hory, N. U. Nguyen et al., "No trend toward a spontaneous improvement of hyperparathyroidism and high bone turnover in normocalcemic long-term renal transplant recipients," American Journal of Kidney Diseases, vol. 29, no. 5, pp. 746-753, 1997.

[48] H. Sperschneider and G. Stein, "Bone disease after renal transplantation," Nephrology Dialysis Transplantation, vol. 18, no. 5, pp. 874-877, 2003.

[49] M. Sundaram, D. Dessner, and S. Ballal, "Solitary, spontaneous cervical and large bone fractures in aluminum osteodystrophy," Skeletal Radiology, vol. 20, no. 2, pp. 91-94, 1991.

[50] K. M. Koch, “Dialysis-related amyloidosis," Kidney International, vol. 41, no. 5, pp. 1416-1429, 1992.

[51] E. Kiss, G. Keusch, M. Zanetti et al., "Dialysis-related amyloidosis revisited," The American Journal of Roentgenology, vol. 185, no. 6, pp. 1460-1467, 2005.

[52] M. Sundaram, M. K. Wolverson, E. Heiberg, and R. D. Grider, "Erosive azotemic osteodystrophy," American Journal of Roentgenology, vol. 136, no. 2, pp. 363-367, 1981.

[53] D. Kuntz, B. Naveau, T. Bardin, T. Drueke, R. Treves, and A. Dryll, "Destructive spondylarthropathy in hemodialyzed patients. A new syndrome," Arthritis \& Rheumatism, vol. 27, no. 4, pp. 369-375, 1984.

[54] S. E. Falbo, M. Sundaram, S. Ballal, D. Domoto, and K. Martin, "Clinical significance of erosive azotemic osteodystrophy: a prospective masked study," Skeletal Radiology, vol. 28, no. 2, pp. 86-89, 1999. 
[55] P. Langevitz, D. Buskila, J. Stewart, D. J. Sherrard, and G. Hercz, "Osteonecrosis in patients receiving dialysis: report of two cases and review of the literature," Journal of Rheumatology, vol. 17, no. 3, pp. 402-406, 1990.

[56] J. D. Spencer, "Spontaneous rupture of tendons in dialysis and renal transplant patients," Injury, vol. 19, no. 2, pp. 86-88, 1988.

[57] N. Jones and C. M. Kjellstrand, "Spontaneous tendon ruptures in patients on chronic dialysis," The American Journal of Kidney Diseases, vol. 28, no. 6, pp. 861-866, 1996.

[58] S. E. Smith, M. D. Murphey, K. Motamedi, M. E. Mulligan, C. S. Resnik, and F. H. Gannon, "From the archives of the AFIP. Radiologic spectrum of paget disease of bone and its complications with pathologic correlation," RadioGraphics, vol. 22, no. 5, pp. 1191-1216, 2002.

[59] C. Dell'Atti, V. N. Cassar-Pullicino, R. K. Lalam, B. J. Tins, and P. N. M. Tyrrell, “The spine in Paget's disease," Skeletal Radiology, vol. 36, no. 7, pp. 609-626, 2007.

[60] T. E. Moore, M. H. Kathol, G. Y. El-Khoury, C. W. Walker, P. W. Gendall, and C. G. Whitten, "Unusual radiological features in Paget's disease of bone," Skeletal Radiology, vol. 23, no. 4, pp. 257-260, 1994.

[61] K. Cortis, K. Micallef, and A. Mizzi, "Imaging Paget's disease of bone-from head to toe," Clinical Radiology, vol. 66, no. 7, pp. 662-672, 2011.

[62] K. Wittenberg, "The blade of grass sign,” Radiology, vol. 221, no. 1, pp. 199-200, 2001.

[63] D. W. Stoller, P. Tirman, and M. Bredella, "Paget disease," in Diagnostic Imaging: Orthopedics, D. W. Stoller, Ed., Amirsys, Salt Lake City, Utah, USA, 1st edition, 2004.

[64] V. Vuillemin-Bodaghi, C. Parlier-Cuau, C. Cywiner-Golenzer, A. Quillard, G. Kaplan, and J.-D. Laredo, "Multifocal osteogenic sarcoma in Paget's disease," Skeletal Radiology, vol. 29, no. 6, pp. 349-353, 2000.

[65] P. Fransen, C. Mestdagh, and G. Dardenne, "Pagetic sarcoma of the calvarium: report of two cases," Acta Neurologica Belgica, vol. 98, no. 4, pp. 352-355, 1998.

[66] I. Fogelman and D. Carr, "A comparison of bone scanning and radiology in the assessment of patients with symptomatic Paget's disease," European Journal of Nuclear Medicine, vol. 5, no. 5, pp. 417-421, 1980.

[67] R. D. Boutin, D. J. Spitz, J. S. Newman, L. Lenchik, and L. S. Steinbach, "Complications in Paget disease at MR imaging," Radiology, vol. 209, no. 3, pp. 641-651, 1998.

[68] G. Ang, D. Feiglin, and A. M. Moses, "Symptomatic and scintigraphic improvement after intravenous pamidronate treatment of Paget's disease of bone in patients with normal serum alkaline phosphatase levels," Endocrine Practice, vol. 9, no. 4, pp. 280283, 2003.

[69] G. J. R. Cook, M. N. Maisey, and I. Fogelman, "Fluorine-18-FDG PET in Paget's disease of bone," Journal of Nuclear Medicine, vol. 38, no. 9, pp. 1495-1497, 1997.

[70] F. Rauch and F. H. Glorieux, "Osteogenesis imperfecta," The Lancet, vol. 363, no. 9418, pp. 1377-1385, 2004.

[71] N. Khandanpour, D. J. A. Connolly, A. Raghavan, P. D. Griffiths, and N. Hoggard, "Craniospinal abnormalities and neurologic complications of osteogenesis imperfecta: imaging overview," RadioGraphics, vol. 32, no. 7, pp. 2101-2112, 2012.

[72] J. D. Mace and N. Kowalczyk, Radiographic Pathology for Technologists, Mosby, St Louis, Mo, USA, 4th edition, 2004.

[73] J. H. Brusin, “Osteogenesis imperfecta," Radiologic Technology, vol. 79, no. 6, pp. 535-551, 2008.
[74] A. G. Ibrahim and H. A. Crockard, "Basilar impression and osteogenesis imperfecta: a 21-year retrospective review of outcomes in 20 patients," Journal of Neurosurgery: Spine, vol. 7, no. 6, pp. 594-600, 2007.

[75] W. C. Verra, H. J. Pruijs, E. J. Beek, and R. M. Castelein, "Prevalence of vertebral pars defects (spondylolysis) in a population with osteogenesis imperfecta," Spine, vol. 34, no. 13, pp. 13991401, 2009.

[76] E. Martin and J. R. Shapiro, "Osteogenesis imperfecta: epidemiology and pathophysiology," Current Osteoporosis Reports, vol. 5, no. 3, pp. 91-97, 2007.

[77] P. Tsipouras, “Osteogenesis imperfecta," in McKusick's Heritable Disorders of Connective Tissue, Mosby, St. Louis, Mo, USA, 5th edition, 1993.

[78] O. Rieker, K. F. Kreitner, and A. Karbowski, "Hyperplastic callus formation in osteogenesis imperfecta: CT and MRI findings," European Radiology, vol. 8, no. 7, pp. 1137-1139, 1998.

[79] I. Dobrocky, G. Seidl, and F. Grill, "MRI and CT features of hyperplastic callus in osteogenesis imperfecta tarda," European Radiology, vol. 9, no. 4, pp. 665-668, 1999.

[80] M. S. Moore, C. M. Minch, R. W. Kruse, H. T. Harcke, L. Jacobson, and A. Taylor, "The role of dual energy X-ray absorptiometry in aiding the diagnosis of pediatric osteogenesis imperfecta," The American Journal of Orthopedics, vol. 27, no. 12, pp. 797-801, 1998.

[81] American College of Radiology, ACR Practice Guidelines for the Performance of Adult Dual or Single X-Ray Absorptiometry (DXA/pDXA/SXA), American College of Radiology, Reston, Va, USA, 2006.

[82] H. S. Eddeine, R. M. Dafer, M. J. Schneck, and J. Biller, "Bilateral subdural hematomas in an adult with osteogenesis imperfecta," Journal of Stroke and Cerebrovascular Diseases, vol. 18, no. 4, pp. 313-315, 2009.

[83] S. C. Emery, N. C. Karpinski, L. Hansen, and E. Masliah, "Abnormalities in central nervous system development in osteogenesis imperfecta type II," Pediatric and Developmental Pathology, vol. 2, no. 2, pp. 124-130, 1999.

[84] L. J. Zhou, P. L. Khong, K. Y. Wong, and G. C. Ooi, "A case of cerebellar hypoplasia in a Chinese infant with osteogenesis imperfecta," Hong Kong Medical Journal, vol. 10, no. 3, pp. 211213, 2004.

[85] M. L. Brooks, C. Gall, A.-M. Wang, R. Schick, and C. L. Rumbaugh, "Osteogenesis imperfecta associated with basilar impression and cerebral atrophy: a case report," Computerized Medical Imaging and Graphics, vol. 13, no. 4, pp. 363-367, 1989.

[86] M. Hayes, G. Parker, J. Ell, and D. Sillence, "Basilar impression complicating osteogenesis imperfecta type IV: the clinical and neuroradiological findings in four cases," Journal of Neurology Neurosurgery and Psychiatry, vol. 66, no. 3, pp. 357-364, 1999.

[87] L. P. Robinson, N. J. Worthen, R. S. Lachman, G. E. Adomian, and D. L. Rimoin, "Prenatal diagnosis of osteogenesis imperfecta type III," Prenatal Diagnosis, vol. 7, no. 1, pp. 7-15, 1987.

[88] S. J. McAllion and C. R. Paterson, "Causes of death in osteogenesis imperfecta," Journal of Clinical Pathology, vol. 49, no. 8, pp. 627-630, 1996.

[89] H. L. Steinbach and W. Russell, "Measurement of the heel-pad as an aid to diagnosis of acromegaly," Radiology, vol. 82, pp. 418422, 1964.

[90] C. G. Cronin, D. G. Lohan, J. N. Mhuircheartigh, C. P. Meehan, J. Murphy, and C. Roche, "CT evaluation of Chamberlain's, McGregor's, and McRae's skull-base lines," Clinical Radiology, vol. 64, no. 1, pp. 64-69, 2009. 
[91] H. E. Albers-Schonberg, "Röntgenbilder einer seltenen Knockenerkrankung," Münchener Medizinische Wochenschrift, vol. 51, pp. 365-368, 1904.

[92] L. L. Ihde, D. M. Forrester, C. J. Gottsegen et al., "Sclerosing bone dys-plasias: review and differentiation from other causes of osteosclerosis," Radiographics, vol. 31, no. 7, pp. 1865-1882, 2011.

[93] Z. Stark and R. Savarirayan, "Osteopetrosis," Orphanet Journal of Rare Diseases, vol. 4, no. 1, article 5, 2009.

[94] P. Beighton, F. Horan, and H. Hamersma, "A review of the osteopetroses," Postgraduate Medical Journal, vol. 53, no. 622, pp. 507-516, 1977.

[95] A. Greenspan, "Sclerosing bone dysplasias: a target-site approach," Skeletal Radiology, vol. 20, no. 8, pp. 561-583, 1991.

[96] J. Bollerslev and L. Mosekilde, "Autosomal dominant osteopetrosis," Clinical Orthopaedics and Related Research, no. 294, pp. 45-51, 1993. 


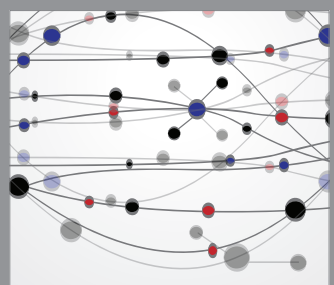

The Scientific World Journal
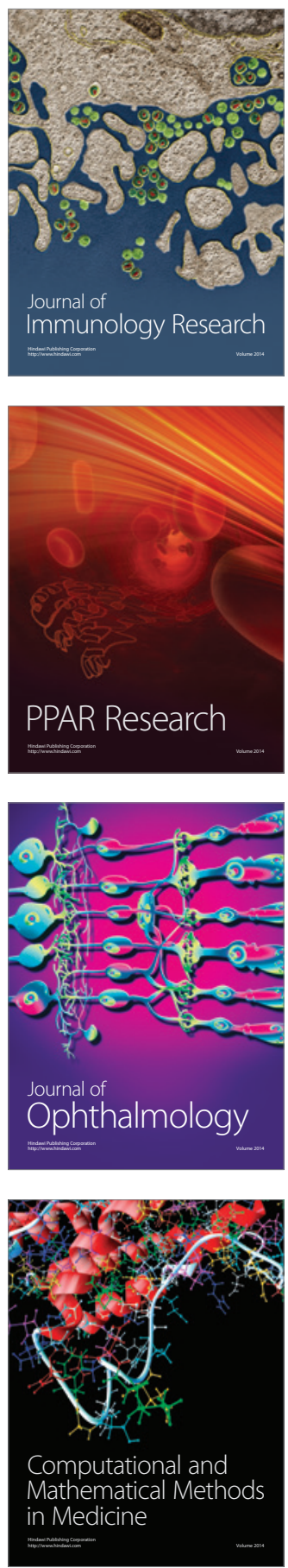

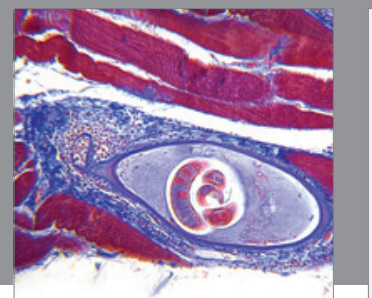

Gastroenterology

Research and Practice
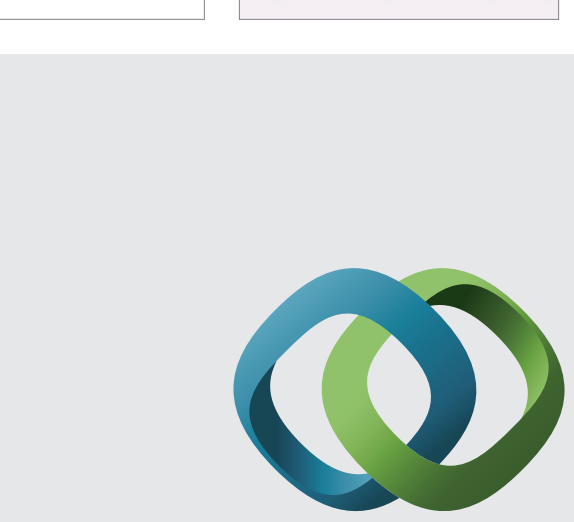

\section{Hindawi}

Submit your manuscripts at

http://www.hindawi.com
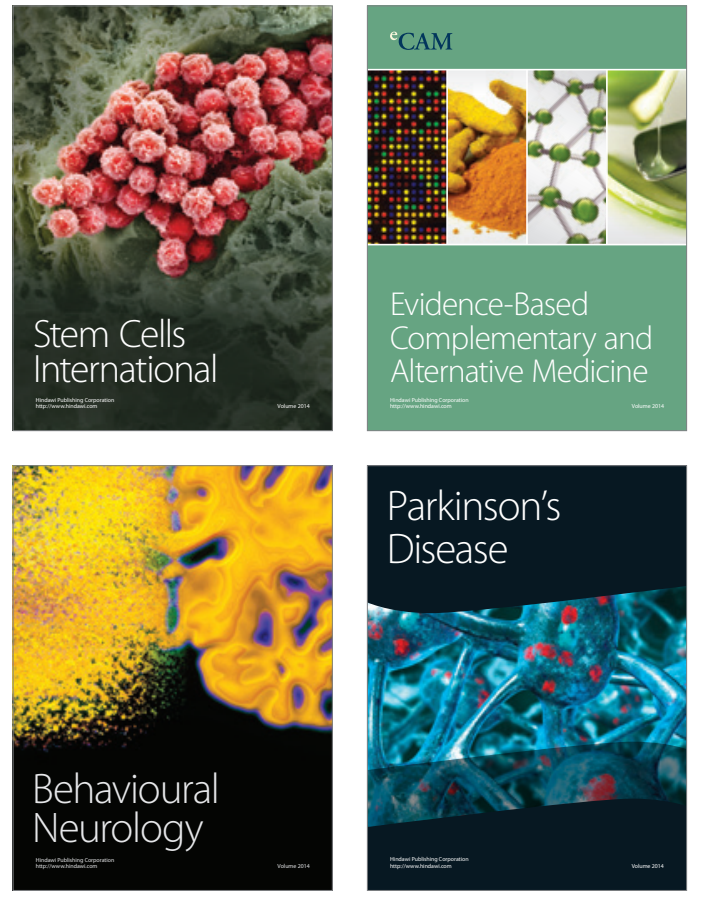
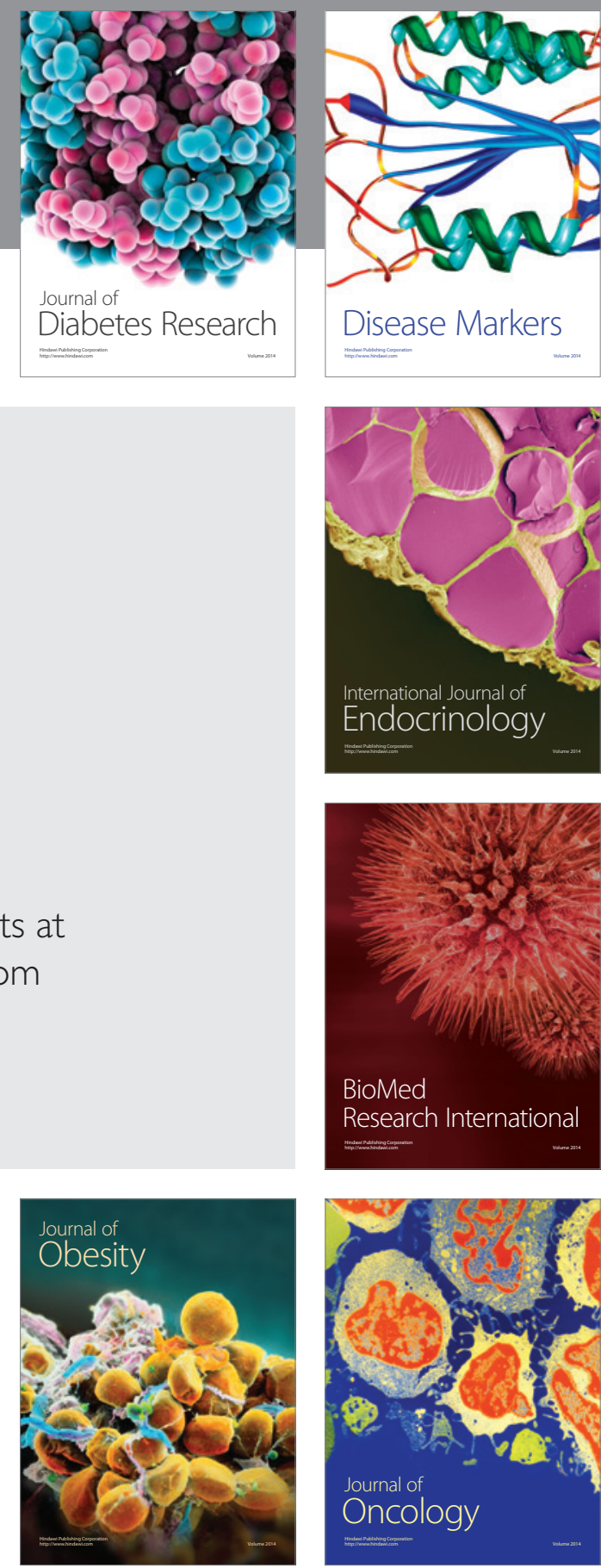

Disease Markers
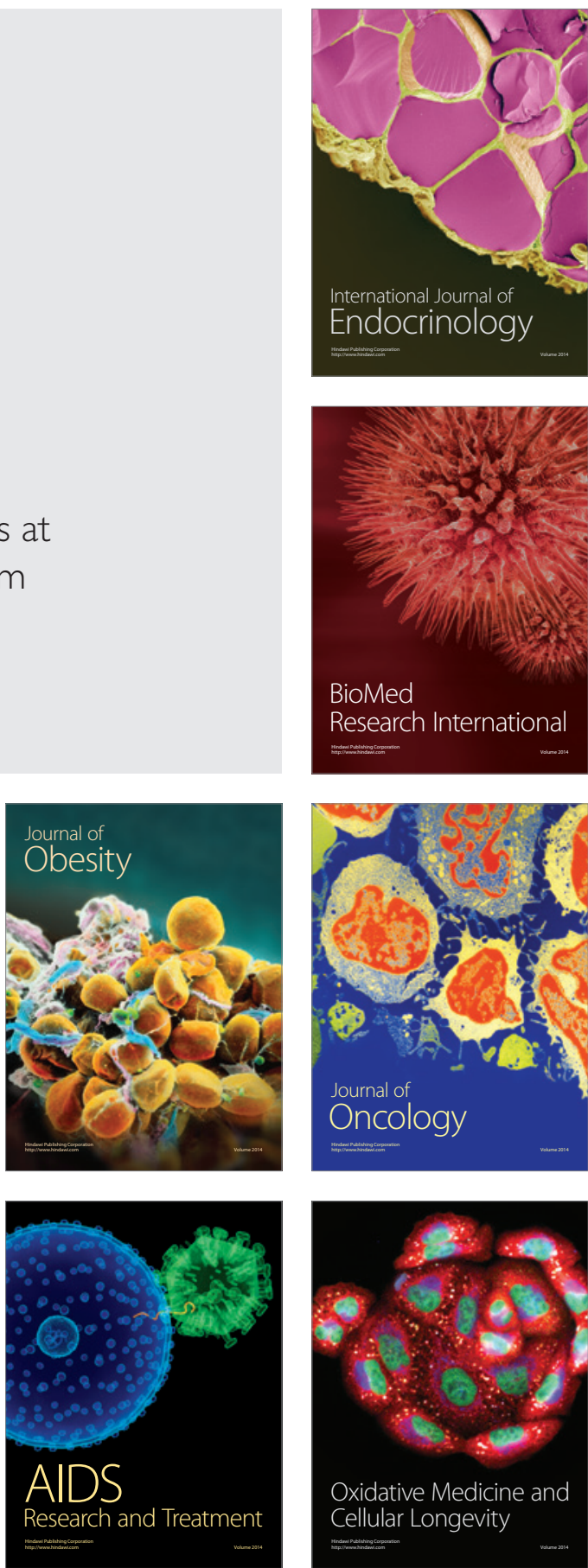